\title{
REGULATION OF CONNEXIN- AND PANNEXIN-BASED CHANNELS BY POST-TRANSLATIONAL MODIFICATIONS
}

Catheleyne D'hondt' ${ }^{1}$, Jegan Iyyathurai ${ }^{1}$, Mathieu Vinken ${ }^{2}$, Vera Rogiers ${ }^{2}$, Luc Leybaert $^{3}$, Bernard Himpens ${ }^{1}$ and Geert Bultynck ${ }^{1}$

${ }^{1}$ Laboratory of Molecular and Cellular Signalling, Department Cellular and Molecular Medicine, KU Leuven, Campus Gasthuisberg 0/N 1, Herestraat 49 bus 802, BE-3000 Leuven, Belgium.

2 Department of Toxicology, Faculty of Medicine and Pharmacy, Vrije Universiteit Brussel, Laarbeeklaan 103, BE-1090 Brussels, Belgium.

3 Department of Basic Medical Sciences - Physiology Group, Faculty of Medicine and Health Sciences, De Pintelaan 185 (Block B, 3 ${ }^{\text {th }}$ Floor), Ghent University, BE-9000 Ghent, Belgium.

Running title: Post-translational modification of connexins and pannexins

\section{Keywords:}

Post-translational modification; Connexin; Pannexin; Hemichannels; Gap junctions.

\section{Word count: 7554}

Figures: 2

\section{Tables: 1}

\section{Corresponding authors:}

C. D'hondt, Ph.D.

G. Bultynck, Ph.D.

Laboratory of Molecular and Cellular Signalling, KU Leuven

Department Cellular and Molecular Medicine

Campus Gasthuisberg, 0/N 1 
Herestraat 49 bus 802

BE-3000 Leuven, Belgium

E-mail: catheleyne.dhondt@med.kuleuven.be and geert.bultynck@med.kuleuven.be 


\begin{abstract}
Connexin (Cx) and pannexin (Panx) proteins form large conductance channels, which function as regulators of communication between neighboring cells via gap junctions and/or hemichannels. Intercellular communication is essential to coordinate cellular responses in tissues and organs, thereby fulfilling an essential role in the spreading of signaling, survival and death processes. The functional properties of gap junctions and hemichannels are modulated by different physiological and pathophysiological stimuli. At the molecular level, Cxs and Panxs function as multi-protein channel complexes regulating their channel localization and activity. In addition to this, gap junctional channels and hemichannels are modulated by different post-translational modifications, including phosphorylation, glycosylation, proteolysis, N-acetylation, Snitrosylation, ubiquitination, lipidation, hydroxylation, methylation and deamidation. These PTMs influence almost all aspects of communicating junctional channels in normal cell biology and pathophysiology. In this review, we will provide a systematic overview of PTMs of communicating junction proteins and discuss their effects on $\mathrm{Cx}$ and Panx-channel activity and localization.
\end{abstract}




\section{General introduction communicating junction proteins}

Three families of proteins, described as connexin (Cx), pannexin (Panx) and innexin (Inx) proteins, are well known to form large conductance channels. Inxs, Cxs and Panxs belong to one superfamily (Baranova et al., 2004; Phelan et al., 1998). The invertebrate Inx family counts 25 genes in C. elegans and 8 Drosophila melanogaster genes (Phelan, et al., 1998; Yen and Saier, 2007). The vertebrate Cx family contains 21 human Cx genes and the vertebrate Panx family of mammalian proteins contains 3 members (Panx1, Panx2 and Panx3). Cxs, Panxs and Inxs are transmembrane proteins consisting of a cytoplasmic N-terminal domain (NT), 4 typical transmembrane domains (TM; TM1, TM2, TM3, TM4), 2 extracellular loop domains (EL1 and EL2), one cytoplasmic loop domain (CL) and a cytoplasmic C-terminal domain (CT) (Fig. 1). Cx and Panx families show structural and functional similarities, including the ability to form gap junction channels and hemichannels. Yet, the role of Panxs as functional gap junction channels on the physiological level remains debated (for review see D'hondt et al., 2009). Moreover, Sosinsky and coworkers claimed that since Panx oligomers are, until now, shown to only form functional channels in unapposed membranes, and they should be referred to as channels and not hemichannels (Sosinsky et al., 2011). Very recently, a new protein family, $\mathrm{Ca}^{2+}$-homeostasis modulator 1 (CALHM1), has been shown to structurally and functionally resemble Cx- and Panx channels (Siebert et al., 2013) and to mediate purinergic signaling from taste buds to the gustatory nerves in response to sweet, bitter and umami taste molecules (Taruno et al., 2013).

In the plasma membrane, these channels function as regulators of communication between neighboring cells, either in a direct way by the formation of gap junction channels, which are formed when two hemichannels of adjacent cells dock, or in an indirect paracrine manner by controlling exchange of ions and metabolites between the intra- and extracellular environment through unopposed hemichannels (reviewed in (D'hondt et al., 2009; D'hondt et al., 2010)). It is evident that gap junction channels and especially hemichannels need to be tightly regulated to assure cell survival. Not surprisingly, different physiological stimuli such as increased intracellular acidification (Morley et al., 1997), altered transmembrane or transjunctional potential (Palacios-Prado and Bukauskas, 2011), changes in intra- and extracellular calcium

concentrations (De Vuyst et al., 2006; De Vuyst et al., 2009)\{Ponsaerts, 2010 
\#394;Ponsaerts, 2012 \#826\} and RhoA signaling \{Derangeon, 2008 \#1026;SeminarioVidal, 2011 \#1025;Ponsaerts, 2012 \#1027\}, have been found to modify the functionality of gap junctions and hemichannels. In addition, numerous proteins have been found to interact with these channels and some have been shown to affect channel localization and activity (Herve et al., 2012). Channel-binding proteins can be modified by proteins with enzymatic activity inducing the so-called post-translational modifications (PTMs) (Johnstone et al., 2012).

In this review, we provide an overview of important and recent PTMs of communicating junction proteins that affect assembly, trafficking and function of $\mathrm{Cx}-$ and Panx-based channels. We will mainly focus on phosphorylation, glycosylation and proteolysis. We organized the description of the PTMs from PTMs for which more is known regarding sites of modification and functional consequences to PTMs for which much less or very little is known.

\section{General introduction PTMs}

The term PTM indicates changes in the polypeptide chain as a result of either the addition or removal of covalent functional groups or proteins. These modifications include phosphorylation, glycosylation, proteolysis, lipidation, N-acetylation, Snitrosylation, ubiquitination, lipidation, hydroxylation, methylation and deamidation.. These PTMs can be reversible (e.g., phosphorylation) or irreversible (e.g., proteolysis, ubiquitination, sumoylation).

Protein PTMs play a key role in many cellular processes such as cellular differentiation (Grotenbreg and Ploegh, 2007), protein degradation (GeissFriedlander and Melchior, 2007), signaling and regulatory processes (Morrison et al., 2002), regulation of gene expression (Vinken et al., 2006), and protein-protein interactions (Larsen et al., 2006). Therefore, identifying and understanding PTMs is critical in the study of cell biology and disease treatment and prevention. Currently, more than 60 types of PTMs are described in dbPTM (http://dbptm.mbc.nctu.edu.tw/), a freely accessible database that contains validated and predicted information on protein PTMs (Lee et al., 2006). 
Traditionally, PTMs have been identified by Edman degradation, thin-layer chromatography, amino acid analysis, isotopic labeling (e.g., [32P]- phosphate incorporation), immunochemistry by applying pan-specific anti-PTM antibodies (e.g., pan- phosphotyrosine) or PTM-site-specific antibodies (e.g., anti-phosphoserine residue 368 of $\mathrm{Cx} 43$ ) and nuclear magnetic resonance (e.g., ${ }^{31} \mathrm{P}-\mathrm{NMR}$ ) (Kee and Muir, 2012; Larsen, et al., 2006). The technique that is now widely used in proteomics to identify PTMs is mass spectrometry (MS) (Aebersold and Mann, 2003; Yates et al., 2005). MS is a robust quantitative technique to identify PTMs by their mass-value and to map the PTM-sites within a protein (Larsen, et al., 2006). In this technique, the mass increment or deficit as a result of PTM-induced changes in molecular weight of the modified amino acids, is measured (Larsen, et al., 2006).

Various PTMs have been reported to alter the regulation and localization of Cxs (Johnstone, et al., 2012). Glycosylation is the PTM that has been studied most extensively for Panxs. To the best of our knowledge, no reports have yet been published about PTMs of Inxs. An overview of PTMs either determined of predicted are presented in figure 1 (for Cxs) and figure 2 (for Panxs).

\section{Communicating junction proteins and PTMs}

\subsection{Phosphorylation}

Protein phosphorylation is a reversible process in which protein functions are regulated by kinase-mediated addition of a phosphate group, principally to serine (S), threonine (T) or tyrosine residues (Y) (Ciesla et al., 2011; Davis, 2011). Many critical events involved in cellular response are mediated by phosphorylation and dephosphorylation, such as regulation of enzymatic activity, protein conformational change, protein-protein interaction, and cellular localization (Davis, 2011; Huttlin et al., 2010; Nishi et al., 2011). Abnormal phosphorylation has been implicated in many severe diseases (Colomer and Means, 2007; Saez et al., 2003).

Cx26, Cx31, Cx32, Cx36, Cx37, Cx40, Cx43, Cx45, Cx46, Cx50 and Cx56 have been 
shown to be phophoproteins (Lampe and Lau, 2000; Lampe et al., 2000; Locke et al., 2009; Saez et al., 1998) (Fig. 1, Table 1). As for many other phosphorylation research fields, Cx-phosphorylation research focused on serine (S), threonine $(\mathrm{T})$ and tyrosine (Y) amino acids via protein kinase B (PKB/Akt) (Dunn et al., 2011), c- and v-src, mitogen-activated protein kinase (MAPK), protein kinase C (PKC), p34cdc2, casein kinase 1 (CK1), protein kinase A (PKA) or calmodulin-dependent protein kinase pathways (Lampe and Lau, 2004; Lampe, et al., 2000; Saez, et al., 1998; Solan and Lampe, 2005, 2009) (Table 1). For Cxs, no phosphorylation events of basic amino acids are described.

In Cxs, phosphorylation of cytoplasmic residues mainly occurs in the C-terminal domain (Cooper et al., 2000; Rikova et al., 2007; Wisniewski et al., 2010), and occasionally in the N-terminal domain (Chen et al., 2012; Wisniewski, et al., 2010) or cytoplasmic loop domain (Alev et al., 2008; Berthoud et al., 1997; Rigbolt et al., 2011) (Fig. 1, Table 1). In multiple tissues, Cxs are regulated by multi-site phosphorylation resulting in altered Cx-protein synthesis and turnover, trafficking, membrane insertion and aggregation. Hence, $\mathrm{Cx}$ phosphorylation is involved in the efficient delivery of hemichannels to the gap junction plaque (Johnson et al., 2012; Palatinus et al., 2011a), gap junction channel assembly, function, and turnover under both normal and disease conditions (Laird, 2005; Lampe and Lau, 2000, 2004; Marquez-Rosado et al., 2011; Saez, et al., 2003; Saez, et al., 1998; Solan and Lampe, 2005, 2007, 2009). However, it is suggested that phosphorylation is neither required for $\mathrm{Cx}$ insertion to the membrane (Musil et al., 1990; Solan and Lampe, 2005) nor for the formation of functional channels (Johnstone et al., 2009; Martinez et al., 2003). Moreover, Cx43 truncated at aa 236 was compromised in trafficking to the membrane, while $\mathrm{Cx} 43$ truncated at aa 239 remained able to traffic to the membrane and form functional gap junction channels, but not functional hemichannels (De Vuyst et al., 2007; Wayakanon et al., 2012). Thus, only a portion of the Cx43 C-terminal domain is shown to be required for its trafficking.

Recently, the effects of phosphorylation on Cx43 structure and function have been extensively reviewed (Jeyaraman et al., 2011; Johnstone, et al., 2012; MarquezRosado, et al., 2011; Solan and Lampe, 2009). A list of Cx43 phosphopeptide sequences and an extensive overview of $\mathrm{Cx} 43$ multi-site phosphorylation (primarily at S) is provided by Chen and coworkers (Chen, et al., 2012). Much less is known for the 
other Cx subtypes. We will first give an overview of $\mathrm{Cx} 43$ phosphorylation and then provide the current state of-the-art of the other Cx subtypes and Panxs. Here, we will focus on the phosphorylation of $\mathrm{Cx} 43$ and the current knowledge about the phosphorylation-dependent regulation of other $\mathrm{Cx}$ and Panx isoforms.

\subsubsection{Phosphorylation of $C x 43$}

The C-terminal domain of $\mathrm{Cx} 43$ plays an important role in the efficient assembly of gap junction channels, which organize into symmetrical arrays resulting in the formation of gap junction plaques (Bruzzone et al., 1996; White et al., 1995). These gap junction plaques are located in the vicinity of adherens and tight junctions forming the junctional complex, which is linked to the actin cytoskeleton via linker molecules such as zonula occludens-1 and -2 (ZO-1 and ZO-2) (reviewed in (Giepmans, 2004)). ZO-1 and ZO-2 interact with Cx43 (Singh et al., 2005) and control Cx43 trafficking to gap junction plaques (Hunter et al., 2005; Jin et al., 2004; Segretain et al., 2004; Toyofuku et al., 1998). The C-terminal domain of Cx43 contains 32 amino acid residues that are phosphorylated by protein kinases (Chen, et al., 2012; MarquezRosado, et al., 2011), 15 residues are S residues that are phosphorylated by $\mathrm{Ca}^{2+} /$ calmodulin protein kinase II (CaMKII) (Huang et al., 2011), a protein kinase regulating $\mathrm{Ca}^{2+}$ homeostasis, transcription, apoptosis, and ischemic heart disease (Colomer and Means, 2007; Gomez et al., 2009; Singh et al., 2012).

Cx43 is phosphorylated on Y265 and Y247 by v-src (Lin et al., 2001; Solan and Lampe, 2008; Swenson et al., 1990). The interaction of src with Cx43 upon phosphorylation at Y265 is shown to regulate the interaction between $\mathrm{Cx} 43$ and $\mathrm{ZO}-1$, but whether src phosphorylation of $\mathrm{Cx} 43$ on Y265 and/or Y247 directly inhibits gap junctional communication or whether MAP kinase phosphorylation of $\mathrm{Cx} 43$ plays a more direct role is still debated (Cottrell et al., 2003; Lin, et al., 2001; Zhou et al., 1999). CK1mediated phosphorylation of C-terminal domain of Cx43 at S364 (TenBroek et al., 2001), S325 (Cooper and Lampe, 2002), S328 (Cooper and Lampe, 2002) and S330 (Cooper and Lampe, 2002) increased gap junction assembly and coupling and enhanced gap junctional communication (Lampe et al., 2006). Consistent with this, CK1 inhibition significantly reduced Lucifer Yellow dye transfer, hinting that CK1mediated Cx43 phosphorylation of S325/S328/S330 contributes to establish 
functional gap junctional channels. These data are fully in line with the recent in vivo findings using knock in-mouse models, in which Cx43-S325A/S328A/S330A hampers gap junction channel functions, while Cx43-S325E/S328E/S330E improves gap junction channel functions (Remo et al., 2011). These mice were highly susceptible to inducible arrhythmias, while the phospho-mimick (Cx43-S325E/S328E/S330E) knock in mice showed a reduced susceptibility to inducible arrhythmias and were resistent to acute and chronic pathological gap junction-remodeling (Remo, et al., 2011).

Phosphorylation of the C-terminal domain Cx43 at Y265 (Toyofuku et al., 2001) and at S372/S373 prevents the interaction with the PDZ2-domain of ZO-1, acting as an on/off switch for interaction of Cx43 with ZO-1 (Chen et al., 2008; Xiao et al., 2011), and thus regulating the formation of gap junction channels (Rhett and Gourdie, 2012). The Z0-1-Cx43 interaction, which is concentrated in a region of the plasma membrane surrounding the gap junction plaque called the perinexus, governs a balance between undocked connexons in the perinexus and connexons docked in functional intercellular channels in the gap junction (Hunter, et al., 2005; Rhett and Gourdie, 2012). Kalcheva and coworkers (Kalcheva et al., 2007) also showed that the I130T mutation interferes with Cx43 phosphorylation. As a consequence, this mutation results in diminished trafficking and assembly of junctional channels, reduced cell-cell coupling, slowing of impulse propagation, and enhanced arrhythmic potential.

Several other studies have linked reduced gap junctional communication to $\mathrm{Cx} 43$ phosphorylation at different sites, namely at Y247 (Solan and Lampe, 2008), at S255 (Cottrell, et al., 2003; Kanemitsu et al., 1998; Lampe et al., 1998; Warn-Cramer et al., 1998), at S262 (Doble et al., 2004; Norris et al., 2008; Solan and Lampe, 2008; Srisakuldee et al., 2009), at Y265 (Solan and Lampe, 2008), at S279 (Cottrell, et al., 2003; Warn-Cramer, et al., 1998), at S282 (Cottrell, et al., 2003; Solan and Lampe, 2008; Warn-Cramer, et al., 1998) and at S368 (Ek-Vitorin et al., 2006; Palatinus et al., 2011b; Richards et al., 2004; Solan and Lampe, 2008; Srisakuldee, et al., 2009; Straub et al., 2009). Direct phosphorylation of Cx43 at S368 also reduced hemichannel opening (Bao et al., 2004). Cx43 phosphorylation at S262 and at S368 occurred during global ischaemia and was accompanied by attenuation of ischaemia-induced $\mathrm{Cx} 43$ dephosphorylation and prevention of $\mathrm{Cx} 43$ lateralization (Srisakuldee, et al., 2009). 
PKCepsilon-dependent Cx43 phosphorylation at S262 is associated with cardioprotection (Srisakuldee, et al., 2009) (Miura et al., 2007). PKC-dependent Cx43 phosphorylation at S368 results in increased Cx43 gap junction-channel permeability, reduced unitary conductance (Ek-Vitorin, et al., 2006), and restored gap junctional communication regulating wound healing (Richards, et al., 2004). Scratch wounding of primary human keratinocytes caused an increase in Cx43 phosphorylation at S368 in cells adjacent to the scratch, and a reduced dye transfer at the edge of the scratch. In vivo, phosphorylation of $\mathrm{Cx} 43$ at S368 was increased in the injury border zone acutely following ventricular injury, which may contribute to reductions in induciblearrhythmia following injury (O'Quinn et al., 2011).

Cx43 internalization from the gap junction plaque as well as Cx turnover (Laird, 2005; Lampe and Lau, 2000) is associated with phosphorylation at S255 and S262 during mitosis (Kanemitsu, et al., 1998; Lampe, et al., 1998), at S365 (Beardslee et al., 2000; Solan and Lampe, 2007) and at S368 (Lampe and Lau, 2000).

Direct phosphorylation of $\mathrm{Cx} 43$, resulting from PKB/Akt activation, controls gap junction stability and is necessary to form larger stable gap junctions (Dunn, et al., 2011). This phosphorylation of $\mathrm{Cx} 43$ may provide important novel insights in the downstream targets of the pro-survival and growth function of Akt signaling in cells. It is important to note that Akt not only phosphorylates $\mathrm{Cx} 43$ channels but also $\mathrm{IP}_{3} \mathrm{R}$ channels to prevent pro-apoptotic $\mathrm{Ca}^{2+}$ signaling (Marchi et al., 2012; Szado et al., 2008)\{Decuypere, 2011 \#1028;Vanderheyden, 2009 \#1029\}. Thus, it is not excluded that Akt may negatively regulate $\mathrm{Cx}$ hemichannels or Panx channels, given their role in cell death (Chekeni et al., 2010; Sandilos et al., 2012)\{Decrock, 2009 \#1035;Decrock, 2012 \#960;Decrock, 2009 \#1034\}.

Also non-channel functions in cell growth are described for Cxs. For instance, a Cxspecific cis-acting gene module, pointed as a Cx-response element in the promoter region, is suggested to modulate the expression of tissue homeostasis gatekeepers. Moreover, the interaction of Cxs with regulators of cell growth and cell death possibly occurs via the interplay of Cxs with a number of key tissue homeostasis determinants like $\beta$-catenin, E-cadherin, ZO proteins, ZO-1-associated nucleic acid binding protein, etc., (reviewed in (Vinken et al., 2011)). The expression of multiple apoptotic genes is 
altered upon knock-down of Cx43 (Iacobas et al., 2003), and the production or the activity of a plethora of tissue homeostasis regulators can be affected by Cx proteins, as single entities (Zhang et al., 2003), hereby possibly affecting the establishment of gap junctional intercellular communication. Cxs, or at least specific parts of Cxs, reside in the cell nucleus, where they might directly affect gene transcription, but the exact mechanisms of these channel-independent actions of Cxs remain largely unknown. Upon forced Cx43 expression, the C-terminal tail portion shows a diffuse distribution in the cell, including the nucleus, resulting in the inhibition of cell growth (reviewed in (Vinken, et al., 2011)). Cx43 overexpression inhibits DNA synthesis independent of cell-cell contacts or coupling in neonatal cardiomyocytes (Doble, et al., 2004). PKCmediated phosphorylation of different Cx43 residues, including S262 (Doble et al., 1996; Doble, et al., 2004; Doble et al., 2000), overrules the Cx43-dependent effect on growth inhibition (Dang et al., 2003) in embryonic and neonatal cardiomyotes. Importantly, Cx43-S262D, a phospho-mimicking Cx43 variant, was severely compromised in inhibiting DNA synthesis. In contrast, Cx43-S262A, a phospho-dead Cx43 variant, was very potent in inhibiting DNA synthesis. Importantly, in the absence of cell-to-cell contacts, Cx43's inhibitory effect on DNA synthesis was not affected by the S262A or S262D mutations, indicating that phosphorylation only regulates Cx43mediated inhibition of DNA synthesis in the presence of cell-to-cell contacts (Doble, et al., 2004). Yet, the ability of phosphorylation of $\mathrm{Cx} 43$ to abolish the inhibition of cell growth by $\mathrm{Cx} 43$ does not require Cx43's ability to form gap junction channel forming ability (Doble, et al., 2004). Thus, it is anticipated that Cx43 phosphorylation on S262 and other sites is a likely mechanism by which mitogens promote DNA synthesis and cardiomyocyte proliferation and growth despite their cell-cell contacts. Besides reducing growth by itself, the $\mathrm{C}$-terminal domain of $\mathrm{Cx} 43$ has been demonstrated to enhance cell motility (increase glioma migration) and is sufficient to induce actin cytoskeleton reorganization (Bates et al., 2007; Crespin et al., 2010).

\subsubsection{Phosphorylation of other Cx isoforms}

For a long time, Cx26, with its very short C-terminal domain, was assumed not to be regulated by phosphorylation (Traub et al., 1989). Detailed studies from Locke and 
coworkers identified Cx26 phosphorylation at T123 in the cytoplasmic loop domain, at T177 in EL2, at S183 and T186 near the border of EL2 and TM4 (Locke, et al., 2009) (Fig. 1, Table 1). The effects of phosphorylation in the cytoplasmic loop domain, a domain in which at least two other Cxs (Cx36 and Cx56) are phosphorylated (Berthoud, et al., 1997; Urschel et al., 2006), remain poorly characterized. T123N is a possible Cx26 deaf missense mutation, but there is no information on the functional effects of mutation at this site (Locke, et al., 2009; Park et al., 2000). According to the Cx26 crystal structure (Maeda et al., 2009), T177 forms a docking interaction with the apposed hemichannel. S183 might play a role in regulating hemichannel docking, since $\mathrm{Cx} 26_{\text {deaf }}$ S183F mutation significantly reduces the formation of junctional channels (de Zwart-Storm et al., 2008).

Cx31 phosphorylation at S263 and S266 regulates Cx31 turnover and increases intercellular communication, but $\mathrm{Cx} 31$ phosphorylation did not affect the intracellular trafficking of gap junction proteins (Diestel et al., 2004). Phosphorylation of S263 is crucial to allow the action of CK1 at S266. A rapid decrease of phosphorylation is shown upon exchange of one (S266) or both serine residues (263 and 266), pointing out the predominant role of phosphorylation at position 263 (Diestel, et al., 2004).

Phosphorylation of Cx32 at S233 (Saez et al., 1990) via either cAMP-dPK or PKC (Saez, et al., 1990; Saez, et al., 1986; Takeda et al., 1989; Traub et al., 1987), is temporally correlated with an increased junctional conductance and an increased intercellular gap junctional communication (Chanson et al., 1996). Also, S229 is phosphorylated, but to a lesser extent than S233 (Saez, et al., 1990). Cx32 is phosphorylated at T243 by the epidermal growth factor receptor (Diez et al., 1995). In addition, alterations in the phosphorylation state of the C-terminal tail of $\mathrm{Cx} 32$ might regulate myelin homeostasis (Stauch et al., 2012).

Cx36 and the fish orthologue Cx35 are targets for multiple kinases (Kothmann et al., 2007; Kothmann et al., 2009; Patel et al., 2006; Urschel, et al., 2006). Phosphorylation of Cx36 was identified at S110, T111, S293 and S315, resulting in an increased synaptic efficacy in the form of "run-up" of junctional conductance in N2A cells expressing Cx36 (Alev, et al., 2008). PKA-mediated phosphorylation of Cx36 was 
associated with a decreased gap junctional communication (Urschel, et al., 2006). In contrast, PKA activation of protein phosphatase $2 \mathrm{~A}$ and subsequent dephosphorylation of Cx36 at S293 results in Cx36 gap junction uncoupling in retinal AII amacrine cells, thus Cx36 phosphorylation is required for AII amacrine cell coupling strength (Kothmann, et al., 2009). This regulation is likely controlled at the level of individual Cx36 plaques and phosphorylation of Ser293 appears to influence permeability of Cx36 gap junctions but not the trafficking of Cx36 (Kothmann, et al., 2009).

Cx37 phosphorylation at S319 mediated by glycogen synthase kinase-3, a kinase known to be implicated in cell proliferation and cancer, was shown to be associated with reduced gap junctional intercellular communication (Morel et al., 2010).

PKA-mediated phosphorylation of Cx40 (probably at S120 or S345, which are the known predicted Cx40 PKA phosphorylation sites (Kemp and Pearson, 1990; Kennelly and Krebs, 1991)) regulates Cx40 gap junction function (van Rijen et al., 2000). In vivo, this may lead to an increase in intercellular conductivity and permeability in the vasculature and the heart where $\mathrm{Cx} 40$ is expressed (van Rijen, et al., 2000).

Cx45 phosphorylation in the C-terminal domain to differentially regulates electrical intercellular conductance via $\mathrm{Cx} 45$ gap junctions. Yet, regulation did not alter the single channel conductance, but most likely modulates the open probability of Cx45 gap junction channels (van Veen et al., 2000). Phosphorylation of Cx45 occurs at S381, S382, S384 and S385. Mutating these serine residues into phospho-dead mutants increased the turnover rate of Cx45 (Hertlein et al., 1998).

Low levels of $\mathrm{Cx} 46$ synthesis and slow rate of $\mathrm{Cx} 46$ phosphorylation was shown in rat embryo lens primary cultures and in bovine organ cultures (Jiang et al., 1993). Cx46 phosphorylation (mainly at T residues (Lin et al., 2004; Zampighi et al., 2005) and for a small fraction at S residues (Lin, et al., 2004)) in the C-terminal domain (also for the bovine orthologue $\mathrm{Cx} 44$ ) (Shearer et al., 2008)was suggested to occur via PKC-gamma activation (Lin, et al., 2004; Saleh et al., 2001). Interestingly, a role for PKC-gamma is 
suggested in control of lens cortical gap junctions (Saleh, et al., 2001).

Cx50 phosphorylation at T residues was shown in in the whole lens (Lin, et al., 2004), and at $\mathrm{S}$ residues in both the C-terminal domain and the central cytoplasmic loop domain in the bovine orthologue $\mathrm{Cx} 49$ (Shearer, et al., 2008). PKC-gamma-mediated phosphorylation at $\mathrm{S}$ and $\mathrm{T}$ residues decreased the density of $\mathrm{Cx} 50$ channels assembled in gap junctions, while increasing the density of Cx50 hemichannels (Zampighi, et al., 2005). In the chicken lens, Cx50 (chicken orthologue is Cx45.6) is phosphorylated in vivo by PKA at S395, resulting in increased gap junction coupling and hemichannel opening, which sustain metabolic coupling and transport in lens fibers (Liu et al., 2011). Cx50 phosphorylation at S395 seemed not responsible for alterations in channel conductance (Liu, et al., 2011). Phosphorylation of Cx50 at S364 (Yin et al., 2000) appears to stimulate Cx50 turnover primarily through proteasome pathway and this phosphorylation inhibits the cleavage of Cx50 by caspase- 3 (Yin et al., 2008).

Cx56 is phosphorylated at S493 and S118 in response to PKC activation using TPA (12-0-tetradecanoyl phorbol 13-acetate). It is suggested that phosphorylation of Cx56 at S118 is involved in the TPA-induced decrease in intercellular communication and acceleration of Cx56 degradation (Berthoud, et al., 1997).

\subsubsection{Phosphorylation of Panxs}

Currently, there is limited information about Panx phosphorylation events, it has been speculated that, in analogy to Cx-phosphorylation, the gating of Panx-based channels would be affected by phosphorylation. Consensus phosphorylation-sites have been suggested based on prediction for Panx1 and Panx3 (Barbe et al., 2006; Penuela et al., 2007) (Fig. 1, Table 1 and Fig. 2A). Very recently, Panx2 seemed to be phosphorylated at S514 (Ultanir et al., 2012), this is the only phosphorylation site that is biochemically confirmed for Panxs. 


\subsection{Glycosylation}

\subsubsection{Glycosylation of CxS}

Cxs proteins seem not to be glycosylated and probably lack potential glycosylation sites in their extracellular loops. The amino termini of several Cxs contain potential consensus N-glycosylation sites. Due to their localization in the cytoplasm and their accesibility to the glycosylating enzymes, they are not utilized (Rahman et al., 1993; Saez, et al., 2003; Wang et al., 1995). However, the activity of Cx43 channels can be altered by preventing protein glycosylation with tunicamycin or by removal of extracellular-located glycans by enzymatic deglycosylation (Wang and Mehta, 1995; Wang, et al., 1995). Also, the formation of Cx43 gap junctions is hampered by oligosaccharide moieties of the glycoproteins of the plasma membranes, while inhibition of glycosylation abrogates these constraints (Wang and Mehta, 1995). Glycosylation of N-cadherin mediated by cell surface sialic acid is also associated with inhibition of $\mathrm{Cx} 43$ traffic to the plaque and reduced $\mathrm{Cx} 43$ gap junction functions in cancer cells (Li et al., 2010).

\subsubsection{Glycosylation of Panxs}

In contrast to $\mathrm{Cx}$ channels, the formation of functional Panx channels at the plasma membrane and the distribution of Panxs are both regulated by glycosylation and by the interaction between Panx family members (Penuela et al., 2009). Glycosylation also plays an important role in trafficking of Panxs to the cell surface.

Panx1 and Panx3 (Boassa et al., 2007; Boassa et al., 2008; Penuela, et al., 2007) and Panx2 (Penuela, et al., 2009) are glycoproteins, consisting of probably only one glycan chain (Penuela, et al., 2009). The consensus site for N-linked glycosylation of Panx1 is in the second extracellular loop on N254 (Penuela, et al., 2007), Panx3 can be glycosylated on N71 (Penuela, et al., 2007) and Panx 2 glycosylation occurs on N86 (Penuela, et al., 2009), both in their first extracellular loop (Fig. 1 and Fig. 2A). Panx1 is shown to exist in three different glycosylation states: a core unglycosylated protein (Gly0), a high mannose-glycosylated protein (Gly1) associated within the ER and a 
complex, extensively glycosylated species (Gly2) that is modified in the Golgi apparatus prior to cell surface delivery, Panx2 is shown to exist only as Gly0 species and Gly1 species and Panx3 exists as Gly1 species and Gly2 species (Boassa, et al., 2007; Boassa, et al., 2008; Penuela, et al., 2007; Penuela, et al., 2009; Prochnow et al., 2009) (Fig. 2B). In vivo, not all Panx isoforms are due to glycosylation. Distinct regulatory mechanisms control Panx1 and Panx3 in the testis, efferent ducts, and in the different regions of the epididymis. Changes in glycosylated Panx isoforms may be regulated by androgens, which may underlie the increased number of isoforms observed following orchidectomy (Turmel et al., 2011). In support of this, Nglycosylation has already been demonstrated to be androgen-dependent in the rat epididymis (Iusem et al., 1984).

Glycosylation was proposed to control Panx1 trafficking to the cell surface (Boassa, et al., 2007). The glycosylation-deficient mutant Panx1 ${ }^{\mathrm{N} 254 \mathrm{Q}}$ (Boassa, et al., 2007), showed trafficking defects and exhibits a more prominent intracellular distribution (Penuela et al., 2008). Upon coexpression with Panx1, the delivery of Panx1 ${ }^{\mathrm{N} 254 \mathrm{Q}}$, is rescued to the cell surface (Boassa, et al., 2008). Consistent with this, the trafficking mutant Panx3-GFP is mainly found at the cell surface upon cotransfection with Panx1, and co-expressing Panx1 ${ }^{\mathrm{N} 254 \mathrm{Q}}$ with Panx3-GFP colocalizes only at intracellular sites (Penuela, et al., 2009). These data suggest that glycosylation-deficient mutant Panx1 ${ }^{N 254 Q}$ hinders the trafficking of Panx3-GFP towards the cell surface. The glycosylation-deficient mutants Panx1 ${ }^{\mathrm{N} 254 \mathrm{Q}}$ and Panx3 ${ }^{\mathrm{N} 71 \mathrm{Q}}$ were shown to be capable of forming functional channels suitable for dye uptake (Penuela, et al., 2007), indicating that a subpopulation of these mutants can traffic to the plasma membrane. In contrast, zfPanx1 ${ }^{\mathrm{N} 246 \mathrm{~K}}$, which is a glycosylation-deficient mutant of zebrafish Panx1, is able to traffic to the cell surface, but showed impaired uptake of ethidium bromide compared with wild type zfPanx1 (Prochnow, et al., 2009). Moreover, Gehi and coworkers provided evidence that Panx1 needs to be glycosylated to the Gly2 species to be properly trafficked to the cell surface, and that the C-terminal domain of Panx1 is crucial for Panx1 delivery and retention at the cell surface (Gehi et al., 2011). In the absence of the C-terminal domain, glycosylation of Panx1 is limited to Gly1 and maturation of Panx1 into Gly2 species is inhibited, resulting in retention of Panx1 in 
the ER (Gehi, et al., 2011). The c-terminaly truncated Panx1 $1^{\mathrm{T} 307}$ is glycosylated primarily to Gly1 species and resides in the intracellular compartments. Intermixing with Panx1 does not result in the rescue of Panx1 $1^{\mathrm{T} 307}$ to the cell surface, moreover Panx1 $1^{\mathrm{T} 307}$ is acting dominantely to reduce the delivery of Panx1 to the cell surface (Gehi, et al., 2011).

Whereas Panx1, even the Gly0 species (Boassa, et al., 2008), and Panx3 are able to traffic to the cell surface to form functional hemichannels, Panx2 mainly resides in the intracellular compartments (Penuela, et al., 2009). Its tempting to assume that the large C-terminal domain of Panx2 hinders its trafficking. Although a subpopulation of Panx2 was detected at the plasmamembrane (Penuela, et al., 2009; Zappala et al., 2006), forming functional Panx2 hemichannels suitable for dye uptake, albeit less well than Panx1 or Panx3 (Penuela, et al., 2009). Interestingly, coexpression of Panx2 with Panx1, reduces this dye uptake compared with Panx1 or Panx2 alone (Penuela, et al., 2009) (reviewed in \{D'hondt, 2010 \#346\}). The level of PTMs of Panx2 seems to be less compared to Panx1 and Panx3 (Penuela, et al., 2009), probably because Panx2 does not exist in Gly2 species.

Besides the crucial role of glycosylation for proper Panx delivery to the cell surface, the transport of Panx1 and Panx3 from the ER to the Golgi apparatus is mediated through COPII vesicles (Bhalla-Gehi et al., 2010). This resembles the delivery process of $\mathrm{Cx} 43$ to the cell surface (Thomas et al., 2005). In the Golgi apparatus Panxs are substrates for further glycosylation to Gly2 species, editing and transport to the cell surface.

In conclusion, a population of all three Panx family members can reside and function at the cell surface as single-membrane channels. The interaction of the different Panx subtypes seem to be highly regulated by the state of glycosylation and their intermixing can significantly affect the functionality of the formed monomeric or heteromeric channels. 


\subsection{Proteolysis}

\subsubsection{Proteolysis of CXS}

Proteolysis has been associated with $\mathrm{Cx} 43, \mathrm{Cx} 46(\mathrm{Cx} 44$ and $\mathrm{Cx} 56$, bovine and chicken orthologue respectively), $\mathrm{Cx} 50$ (Cx49 and $\mathrm{Cx} 45.6$ bovine and chicken orthologue respectively) and Panx1 (Fig. 1). Endogenous C-terminal tail truncation has been described of $\mathrm{Cx} 43, \mathrm{Cx} 50$, and the presence of a free C-terminal fragment of $\mathrm{Cx} 43$ is observed in cultured cells (Joshi-Mukherjee et al., 2007) (Fig. 1). Gap junction channel properties and hence gap junctional intercellular communication are altered by Cterminal domain-truncation of $\mathrm{Cx} 43$ (Bates, et al., 2007). Yet, no evidence was found for alterations in motility as a result of this truncation (Bates, et al., 2007; Moorby, 2000).

Autophagy was shown to be involved in proteolysis of the wild-type Cx50 and Cx43 (Lichtenstein et al., 2011). Colocalization of intracellular Cxs with p62, a protein that might serve as a cargo receptor for autophagic degradation, was detected. Moreover, treatment with chloroquine, a lysosomal protease inhibitor, blocked the starvationinduced decrease in Cx levels (Lichtenstein et al., 2011). This is fully supported by a recent report showing that gap junctions, following internalization, are degraded by autophagy (Fong et al., 2012). Autophagy is also shown to modulate the internalization and degradation of $\mathrm{Cx} 43$ by ubiquitinylation of plasma membrane Cxs (Bejarano et al., 2012).

Cx46 and $\mathrm{Cx} 50$, which are expressed in human lens fiber cells in the lens core (Donaldson et al., 1992; Paul et al., 1991; White et al., 1992) undergo proteolytic cleavage of their $\mathrm{C}$ termini during fiber maturation. $\mathrm{Cx} 46$ and $\mathrm{Cx} 50$ are important for lens growth and transparency (Gong et al., 2007). Absence of Cx46 and Cx50, resulting in aberrant gap junction communication, resulted in different types of cataracts by affecting lens inner fiber cells (Xia et al., 2006). Nuclear cataracts caused by disruption of $\mathrm{Cx} 46$ in mice were associated with the proteolysis of gamma-crystallins (Gong et al., 1997)(Xia, et al., 2006), leading to its aggregation and subsequent opacification of the lens (Baruch et al., 2001). The $\mathrm{Ca}^{2+}$-dependent cysteine protease (calpain) Lp82 is 
shown to be a key initiator of gamma-crystallin proteolysis (Baruch, et al., 2001), implying a crucial role for $\mathrm{Cx} 46$ gap junctions in maintaining $\mathrm{Ca}^{2+}$ homeostasis and hence controlling calpain Lp82 (Baruch, et al., 2001). Also age-related cataracts in Cx46-knock-out mice are the result of increased intracellular $\left[\mathrm{Ca}^{2+}\right]$, thereby activating the calpain3 isoform Lp82/85 (Tang et al., 2007). Cleavage of Cx46 is also associated with a spatial redistribution of gap junction plaques in the lens (Jacobs et al., 2004). Cx44, the bovine orthologue for Cx46 is cleaved at L255 (Shearer, et al., 2008). Advances in basic research and discoveries of clinical disorders of Cx46 and Cx50 dysfunctions that are associated with cataractogenesis and lens development are reviewed in (Jiang, 2010).

Two calpain-cleavage sites (E290 and S300) were identified in Cx50 (Lin et al., 1997). Also Cx49, the bovine orthologue for Cx50 (Rao et al., 1990), is cleaved by calpain at E290 (Lin, et al., 1997; Shearer, et al., 2008) and S300 (Lin, et al., 1997). C-terminal truncation of $\mathrm{Cx} 50$ did not inhibit the formation of homotypic or heterotypic channels. However, a significant decrease in conductance was observed for truncated channels, a phenomenon independent of alterations in voltage-gating sensitivity, kinetics, or chemical gating (DeRosa et al., 2006). Cx45.6, the chicken orthologue of Cx50, is a direct target of caspase- 3 and the cleavage by caspase-3 between G361 and E367 leads to the development-associated truncation of $\mathrm{Cx} 45.6$, which can be modulated by the specific Cx phosphorylation (Yin et al., 2001; Yin, et al., 2000; Yin, et al., 2008).

\subsubsection{Proteolysis of Panxs}

Panx1 is a target of caspase 3 and 7-mediated proteolysis. Two caspase cleavage sites were identified, namely in the cytoplasmic loop domain at aa 164-167 (DMRD) and at the C-terminal domain at aa 376-379 (DVVD) (Fig. 1, Fig. 2A). Caspase-mediated cleavage of the C-terminal domain of Panx1 is necessary for the induction of Panx1mediated plasma membrane permeability during apoptosis. Expression of truncated Panx1 (at the putative caspase cleavage site) resulted in a constitutively open channel (Chekeni, et al., 2010). This is underpinned by a very recent study showing that caspase cleavage of Panx1 leads to activation of the channel by dissociation of the Cterminal domain from the channel pore (Sandilos, et al., 2012). These results suggest that the intact, pore-associated C-terminal domain inhibits the full-length hPANX1 
channel. Consequently caspase-mediated cleavageof Panxs removes the key inhibitory C-terminal domain determinants, thereby activating hPanx1 (Sandilos, et al., 2012).

\subsection{N-Acetylation}

\subsubsection{Acetylation of Cxs}

Acetylation in Cxs may be involved in regulation of gating and permeability of Cxs, since the $\mathrm{N}$ termini of Cxs regulate channel gating and permeability (Oh et al., 2000; Oh et al., 1999; Purnick, Benjamin, et al., 2000; Purnick, Oh, et al., 2000; Verselis et al., 1994). Moreover, the first 10 residues of Cx26 and Cx32 has been suggested to lie in the channel pore (Purnick, et al., 2000).

In Cx44 and Cx49, the N-terminal M-residue is endogenously removed and the newly exposed N-terminal G-residue becomes acetylated (Shearer, et al., 2008).

Multiple acetylations sites were identified in the cytoplasmic loop domain of Cx26, a region involved in gating by $\mathrm{pH}$ and intramolecular interactions in many Cxs (Fig 1) (Manthey et al., 2001; Ponsaerts et al., 2010; Shibayama et al., 2006). Acetylation was identified at M1 by MS/MS (tandem mass spectrometry) and at K15, K102, K103, K105, K108, K112 and K116 by MS (Locke, et al., 2009) (Fig. 1).

$\mathrm{N}$-terminal acetylation occurs in all proteins with the M1D2 sequence, such as Cx26, hereby eliminating its positive charge. This can have a profound impact on $\mathrm{Cx}$-channel gating, since the $\mathrm{N}$-terminal domain folds into the aqueous pore to act as a voltage sensor and gate in Cxs (Maeda, et al., 2009; Oh et al., 2004; Oshima et al., 2007; Purnick, et al., 2000).

In Cx26, acetylation at K15 may affect charge selectivity to permeants and/or voltage gating, since K15 is located at the outer edge of the cytoplasmic entrance/vestibule of the channel pore near the 'hinge' region at which the N-terminal domain turns into the pore to form the voltage sensor/gate (Maeda, et al., 2009; Purnick, et al., 2000). Several internal K-residues are potentially acetylated in the Cx26 cytoplasmic loop domain near TM2. The Cx cytoplasmic loop domain is involved in gating by $\mathrm{pH}$ and related intramolecular interactions (Manthey, et al., 2001; Shibayama, et al., 2006), so 
dynamic modulation of the charge of this domain by multiple acetylations could modulate these processes, as occurs in other proteins (Yang and Seto, 2008).

A portion of bovine $\mathrm{Cx} 44$ and $\mathrm{Cx} 49$ is acetylated. $\mathrm{N}$-acetylation of the newly exposed $\mathrm{N}$ termini was shown to occur upon removal of the N-terminal Met residue (Shearer, et al., 2008).

$\mathrm{N}($ epsilon)-lysine acetylation of $\mathrm{Cx} 43$ inhibits its association to gap junctions at intercalated discs and may have physiopathological consequences for cell to cell coupling and cardiac function (Colussi et al., 2011).

Acetylation may also regulate $\mathrm{Cx}$ protein levels. Histone deacetylase inhibitors (like Trichostatin A (TSA)), which interfere with the acetylation of core histones, affect the chromatin structure and thus the gene expression (Papeleu et al., 2005; Vanhaecke et al., 2004). TSA differentially affected Cx protein levels and localization and to enhanced gap junctional intercellular communication in primary rat hepatocyte cultures. TSA treatment increased Cx32 protein levels and Cx43 accumulation in the nuclear compartment of primary cultured hepatocytes. TSA treatment resulted in a decrease of Cx26 protein levels and Cx26 was preferentially located in the cytosol of cultured cells (Vinken, et al., 2006).

\subsubsection{Acetylation of Panxs}

Panx1 acetylation sites were predicted at K202, K203 and K211 and Panx2 acetylation sites at K456 and K459 (Fig. 1, Fig. 2A). But no functional evidence is provided for acetylation of Panxs.

\subsection{S-Nitrosylation}

\subsubsection{Nitrosylation of CXS}

The NO donor S-nitroso-N-acetylpenicillamine significantly reduced dye transfer through Cx37 gap junction channels in cultured human umbilical vein endothelial cells (Kameritsch et al., 2005). According to this study, also electrical coupling of Cx37 gap junction channels was reduced upon application of NO in microvascular endothelial 
cells (McKinnon et al., 2009). Recently, Straub and coworkers found that Cx43 is constitutively S-nitrosylated on C271 (Fig. 1), this modification might regulate gap junction channel permeability at the myoendothelial junctions, which are anatomic structures that facilitate direct smooth muscle cell and endothelial cell communication within the resistance artery, in the blood vessel wall (Straub et al., 2011).

Also, Cx hemichannels seem to be regulated by S-nitrosylation. Metabolic inhibition increases the number of $\mathrm{Cx} 43$ hemichannels on the cell surface, and enhances dye uptake. This is associated with multiple molecular changes, including S-nitrosylation of intracellular Cx43 C-residues (Retamal et al., 2006; Retamal et al., 2007). In cardiomyocytes and cortical astrocytes, opening of $\mathrm{Cx} 43$ hemichannels induced by hypoxia, oxygen deprivation or during long periods of ischemia might be mediated by dephosphorylation of $\mathrm{Cx} 43$ hemichannels or by oxidative modification due to increased NO-production (and other reactive oxygen species) (Bao, et al., 2004; Kim et al., 1999). Also, regulation of Cx46 hemichannels by NO has been suggested (Retamal et al., 2009).

\subsubsection{Nitrosylation of Panxs}

Currently, evidence for a direct modulation of Panx1 channels by S-nitrosylation is lacking. Although, since Panx1 contains multiple cysteine residues and since Panx1 is expressed in tissues with enhanced NO production, it is not unlikely that Panx1 channels undergo S- nitrosylation. Furthermore, mutation of C346 in the carboxyl terminus of Panx1 (Bunse et al., 2010) and of C40 in the pore-lining region of the first transmembrane domain of Panx1 results in a constitutively leaky channel (Bunse et al., 2011), indicating the importance of Panx1 cysteine residues in regulating channel gating and permeability (Fig. 1, Fig. 2A).

Moreover, Panx1 and Panx2 channels have been implicated in ischemia-induced neuronal cell death, a condition in which NO production is markedly enhanced (Bargiotas et al., 2011). In line with this, Panx hemichannel opening may mediate excessive NO generation and neuronal cell death during ischemia. This was attenuated by NO synthase inhibitor or reduction of oxidized sulfhydryl groups with the reducing agent DTT (Zhang et al., 2008). Further studies are required to unravel the effect of S- 
nitrosylation on Panx channel gating and permeability.

\subsection{Ubiquitination and sumoylation}

\subsubsection{Ubiquitination of CxS}

Ubiquitination of Cxs with the focus on intracellular trafficking and degradation of $\mathrm{Cx}$ proteins has been reviewed in (Leithe and Rivedal, 2007) (Fig. 1).

Cx43 is monoubiquitinated at K9 and K303 (Wagner et al., 2011). PKC- and MAPKmediated ubiquitination of $\mathrm{Cx} 43$ at the plasma membrane probably regulates $\mathrm{Cx} 43$ endocytosis. Moreover, Nedd4-mediated ubiquitination of Cx43 in the plasma membrane, which is modulated by $\mathrm{Cx} 43$ phosphorylation (Leithe and Rivedal, 2007), seems required to initiate autophagy-dependent internalization and degradation of Cx43 (Bejarano, et al., 2012). In line with this study, also the ubiquitin-binding protein p62/sequestosome 1 was identified in targeting internalized $\mathrm{Cx} 43$ gap junctions to autophagic degradation (Fong, et al., 2012).

Ubiquitination of $\mathrm{Cx} 43$ does neither control gap junction stability nor $\mathrm{Cx} 43$ turnover, since a mutant $\mathrm{Cx} 43$ with all lysines converted to arginines behaved similarly to wild type $\mathrm{Cx} 43$ in the presence of proteasomal and lysosomal inhibitors (Dunn, et al., 2011).

Cx46-induced Cx43 degradation is likely mediated by the ubiquitin-proteasome pathway, involving the intracellular domain of the C-terminal tail of Cx46 (Banerjee et al., 2011).

Very recently, Kjenseth and coworkers were the first to identify $\mathrm{Cx} 43$ as a SUMOylation target protein at K144 or K237, thus Cx43 gap junctions may be regulated by the SUMO system (Kjenseth et al., 2012) (Fig. 1).

\subsubsection{Ubiquitination of Panxs}

Panx1 is shown to be ubiquitinated at K381 and K409 (Kim et al., 2011) (Fig. 1, Fig. 2A), but functional evidence remain elusive. 


\subsection{Lipidation}

\subsubsection{Lipidation of Cxs}

Although it is well established that Cxs are associated with lipid rafts (Locke et al., 2005), only a few reports of lipidation in Cxs exist. Palmitoylation of the end of the Cterminal domain of $\mathrm{mCx} 32$ (residues 277-283) (Locke et al., 2006) and palmitoylation of one or both cysteines in the carboxyl-terminal CSAC sequence of the C-terminal domain of Cx32 (Linder and Deschenes, 2003) is described and the "unspecified prenylation" of $\mathrm{Cx} 32 \mathrm{C}_{280} \mathrm{SAC}_{283}$ in transfected COS cells (Huang et al., 2005) was shown to be geranylation (Locke, et al., 2006) (Fig. 1).

\subsubsection{Lipidation of Panxs}

Panx2 has a depalmitoylated $(\sim 60 \mathrm{kDa})$ form, which resides primarily at the plasma membrane, while the palmitoylated form of Panx2 ( $\sim 85 \mathrm{kDa})$ was suggested to reside in the Golgi and/or ER (Swayne et al., 2010). The exact site where the palmitoylation occurs is not known yet.

\subsection{Hydroxylation}

Hydroxylation occurs in the N-terminus of Cx32 at either N2 or N14 (Locke, et al., 2006) and in Cx26 at N14 in the N-terminal domain, at N113 in the cytoplasmic loop, and at either N170 or N176 in the second extracellular loop (Locke, et al., 2009; Locke, et al., 2006) (Fig. 1).

$\mathrm{N} 14 \mathrm{Y}$ and $\mathrm{N} 14 \mathrm{~K}$ are two $\mathrm{Cx} 26_{\text {deaf }}$ mutations at N14 that affect gating, the N14Y mutation leads to reduced junctional conductance, and $\mathrm{N} 14 \mathrm{~K}$ mutation generates functional channels, but they lack voltage-dependence (Arita et al., 2006; Maeda, et al., 2009; Purnick, et al., 2000). Because N14K does not introduce a charge, this mutation may be a better mimick for the lack of hydroxylation. N176 might be directly involved in the docking interaction between apposed hemichannels (Maeda, et al., 2009). 


\subsection{Methylation}

In Cx26, K61, R75 and either K221 or K223 were defined as methylation sites (Locke, et al., 2009) (Fig. 1). Importantly, R75 in Cx26 is affected by disease-causing mutations in Cx26. For instance, R75Q or R75W mutations in Cx26 fail to form functional junctional channels, display altered voltage-dependence and permeability and act as dominant negative with other Cxs including Cx26. A role of uncoupled R75W channels in the death of cochlear cells and in dominant deafness is possible and this has been associated with Palmoplantar keratoderma (Chen et al., 2005; Deng et al., 2006; Richard et al., 1998).

\subsection{Deamidation}

In the C-terminal domain of Cx43, deamidation occurs at N329 and Q333(Huang, et al., 2011) (Fig. 1). In bovine Cx49, deamidation occurs on N121 (Shearer, et al., 2008). Biochemical evidence still needs to be provided.

\section{Conclusion}

Although important insights have been gained regarding PTMs as a regulatory mechanism for Cx and Panx communicating channels at the cellular level and PTMtarget sites have been associated with disease-causing mutations, still in vivo proof for the relevance of PTM-dependent $\mathrm{Cx}$ - and Panx-channel regulation is often lacking. Thus, mutations in $\mathrm{Cx}$ and Panx-coding genes may lead to the defective $\mathrm{Cx}$ and Panx channels, in part because they lack PTMs essential for their function as communicating channels in controlling physiological processes. Recently this has been shown in a Cx43-phosphorylation dead- and Cx43-phosphorylation mimickknock-in mouse model (Remo, et al., 2011). Given the central role of PTMs in controlling many cell biological aspects of and functional properties of $\mathrm{Cx}$ and Panx 
channels, unequivocally establishing their relevance in vivo and in pathological conditions will be important. PTM directly affect the activity, trafficking, localization and expression of gap junction channels. Furthermore, given the fact that both Cxs and Panxs can form gap junction channels and hemichannels (Ishikawa et al., 2011; Kar et al., 2012; Wang et al., 2012) and the emerging roles for Cx hemichannels in physiological processes (Kar, et al., 2012; Stehberg et al., 2012), it will be important to elucidate how PTMs influence both channel types. PTMs does not necessarily need to exert the same outcome on gap junctions versus hemichannels, as molecular events like intramolecular loop/tail interactions underlying their opening and closing may have opposite outcomes (Evans et al., 2012; Ponsaerts, et al., 2010; Ponsaerts et al., 2012). Finally, beyond phosphorylation events, it is critical to understand how other chemical modifications of $\mathrm{Cx}$ and Panx proteins (like S-nitrosylation, acetylation and deamidation) regulate their activity and how these are altered during pathological conditions. 


\section{List of abbreviations}

Cx: connexin

Panx: pannexin

Inx: innexin

PTM: post-translational modification

MS: mass spectrometry

S: serine residue

T: threonine residue

Y: tyrosine residue

PKB: protein kinase B

MAPK: mitogen-activated protein kinase

PKC: protein kinase $\mathrm{C}$

CK1: casein kinase 1

PKA: protein kinase A

CaMKII: $\mathrm{Ca}^{2+} /$ calmodulin protein kinase II

ZO: zonula occludens

ER: endoplasmic reticulum

$\mathrm{K}$ : lysine residue

TSA: Trichostatin A

NO: nitric oxide

\section{Acknowledgements}

Research work performed in the laboratory was supported by grants from the Research Foundation - Flanders (FWO; grant numbers G.0545.08 and G.0298.11), the Interuniversity Attraction Poles Program (Belgian Science Policy; grant number P7/13) and is embedded in an FWO-supported research community. CDH is a postdoctoral fellow of the Research Foundation - Flanders (FWO). There is no conflict of 
interest to declare. 


\section{Tables and Figures:}

\section{Table 1 Phosphorylation of connexins and pannexins}

Known phosphorylation sites for different connexin and pannexin subtypes, their modifying enzymes and the functional concequences of the phosphorylation.

$\mathrm{AA}=$ number of amino acids

MW = Molecular weight

$\mathrm{BIP}=$ Basal Isoelectric point

$\mathrm{NT}=$ cytoplasmic N-terminal domain

$\mathrm{TM}=$ transmembrane domain (TM; TM1, TM2, TM3, TM4)

$\mathrm{EL}=$ extracellular loop domain (EL1 and EL2)

$\mathrm{CL}=$ cytoplasmic loop domain

$\mathrm{CT}=$ cytoplasmic C-terminal domain

P-site $=$ phosphorylation site

1 (Locke, et al., 2006), 2 (Locke, et al., 2009), 3 (Park, et al., 2000), 4 (de Zwart-Storm, et al., 2008), 5 (Diestel, et al., 2004), 6 (Saez, et al., 1990), 7 (Chanson, et al., 1996), 8 (Stauch, et al., 2012), 9 (Diez, et al., 1995), 10 (Alev, et al., 2008), 11 (Urschel, et al., 2006), 12 (Patel, et al., 2006), 13 (Kothmann, et al., 2009), 14 (Saito et al., 2000), 15 (Morel, et al., 2010), 16 (Kemp and Pearson, 1990), 17 (Kennelly and Krebs, 1991), 18 (van Rijen, et al., 2000), 19 (Huang, et al., 2011), 20 (Swenson, et al., 1990), 21 (Lin, et al., 2001), 22 (Solan and Lampe, 2008), 23 (Cottrell, et al., 2003), 24 (Zhou, et al., 1999), 25 (Warn-Cramer, et al., 1998), 26 (Warn-Cramer et al., 1996), 27 (Norris, et al., 2008), 28 (Lampe and Lau, 2000), 29 (Lampe, et al., 1998), 30 (Kanemitsu, et al., 1998), 31 (Arnold et al., 2005), 32 (Sato et al., 2008), 33 (Laird, 2005), 34 (Xie et al., 1997), 35 (Axelsen et al., 2006), 36 (Bao, et al., 2004), 37 (Doble, et al., 2000), 38 (EkVitorin, et al., 2006), 39 (Dang et al., 2006), 40 (Solan and Lampe, 2007), 41 (Doble, et al., 2004),42 (Srisakuldee, et al., 2009), 43 (Miura, et al., 2007), 44 (Dang, et al., 2003), 45 (Giepmans et al., 2001), 46 (Toyofuku, et al., 2001), 47 (Bellei et al., 2008), 48 (Malone et al., 2007), 49 (Procida et al., 2009), 50 (Guo et al., 2008), 51 (Huang et al., 2007), 52 (Brill et al., 2009), 53 (Munton et al., 2007), 54 (Remo, et al., 2011), 55 (Cooper and Lampe, 2002), 56 (Lampe, et al., 2006), 57 (Paulson et al., 2000), 58 (Shah et al., 2002), 59 (Britz-Cunningham et al., 1995), 60 (TenBroek, et al., 2001), 61 (Yogo et al., 2002), 62 (Beardslee, et al., 2000), 63 (Faigle et al., 2008), 64 (Lurtz and 
Louis, 2007), 65 (Richards, et al., 2004), 66 (Palatinus, et al., 2011a), 67 (Straub, et al., 2009), 68 (Solan et al., 2003), 69 (Saez et al., 1997), 70 (Park et al., 2007), 71 (van Veen, et al., 2000), 72 (Hertlein, et al., 1998), 73 (Saleh, et al., 2001), 74 (Lin, et al., 2004), 75 (Zampighi, et al., 2005), 76 (Shearer, et al., 2008), 77 (Liu, et al., 2011), 78 (Yin, et al., 2001), 79 (Yin, et al., 2008), 80 (Berthoud, et al., 1997), 81 (Ultanir, et al., 2012),

\section{Figure 1}

Schematic representation of the sites for post-translational modifications of communicating junction proteins. The post-translational modification sites are predicted sites that were identified using phosphoproteomic strategies.

Each modification is represented by another color. "B" means bovine orthologue; "C" means chicken orthologue.

Black $=$ Phosphorylation sites

Orange $=$ Glycosylation sites

Pink = Proteolysis sites

Dark blue $=$ Lipidation sites

Purple $=$ S-nitrosylation sites

Red $=$ Acetylation sites

Grey $=$ Deamidation sites

Turquoise blue $=$ Hydroxylation site

Green = Ubiquitination site

Brown $=$ Methylation sites

NT = cytoplasmic N-terminal domain

$\mathrm{TM}=$ transmembrane domain (TM; TM1, TM2, TM3, TM4)

$\mathrm{EL}=$ extracellular loop domain (EL1 and EL2)

$\mathrm{CL}=$ cytoplasmic loop domain

$\mathrm{CT}=$ cytoplasmic C-terminal domain 
(see text and table 1 for references) 


\section{Figure 2}

A. Schematic representation of the transmembrane topology of the three pannexin family members. Based on sequence analysis, Panxs are predicted to contain predicted N-glycosylation (orange residues) (Penuela, et al., 2007), phosphorylation (black) sites (Penuela, et al., 2007), proteolysis (pink) sites (Chekeni, et al., 2010), acetylation (red) sites, S-nitrosylation (purple) sites (Bunse, et al., 2010) and ubiquitination (green) sites (Kim, et al., 2011) $\left(^{*}=\right.$ site is biochemically confirmed). Panx1 (426 amino acids (aa)), Panx2 (667 aa) and Panx3 (392 aa) are integral membrane proteins consisting of 4 transmembrane (TM) domains (numbers indicate the aa position of TM domains), 2 extracellular loops and 1 intracellular loop. Panx1 has a N-glycosylation site at N254, Panx2 has a predicted N-glycosylation site at N86, and Panx3 at N71. (Modified from (Penuela, et al., 2009), http://www.ncbi.nlm.nih.gov/entrez/query.fcgi?cmd=Retrieve\&db=PubMed\&dopt=C itation\&list_uids=19692571)

B. Panx1 and Panx3 are glycosylated to both a high-mannose form (Gly1) and a complex, extensively glycosylated form (Gly2), while Panx2 has only been reported as a high-mannose form (Gly1) or a core unglycosylated isoform (Gly0).

C. Formation of pannexin channels. Homomeric Panx1 (Bruzzone et al., 2005; Dvoriantchikova et al., 2006) and Panx3 (Penuela, et al., 2007) but not Panx2 (Bruzzone et al., 2003) hemichannels are formed. Heteromeric Panx1/Panx2 (Penuela, et al., 2009) and Panx1/Panx3 (Penuela, et al., 2009) hemichannels can be formed, no reports on Panx2/Panx3 hemichannels. Formation of pannexin gap junction channels is still debated (\$) (reviewed in (D'hondt, et al., 2009), (Sosinsky, et al., 2011)). Yet, homotypic Panx1 (Bruzzone, et al., 2003), homotypic Panx3 [249] and heterotypic Panx1/Panx2 (Bruzzone, et al., 2005; Bruzzone, et al., 2003; Dvoriantchikova, et al., 2006) gap junction channels have been described. 


\section{REFERENCES}

Aebersold, R., and Mann, M. (2003). Mass spectrometry-based proteomics. Nature, 422, 198-207.

Alev, C., Urschel, S., Sonntag, S., et al. (2008). The neuronal connexin36 interacts with and is phosphorylated by CaMKII in a way similar to CaMKII interaction with glutamate receptors. Proc Natl Acad Sci U S A, 105, 20964-20969.

Arita, K., Akiyama, M., Aizawa, T., et al. (2006). A novel N14Y mutation in Connexin26 in keratitis-ichthyosis-deafness syndrome: analyses of altered gap junctional communication and molecular structure of $\mathrm{N}$ terminus of mutated Connexin26. Am J Pathol, 169, 416-423.

Arnold, J. M., Phipps, M. W., Chen, J., and Phipps, J. (2005). Cellular sublocalization of Cx43 and the establishment of functional coupling in IMR-32 neuroblastoma cells. Mol Carcinog, 42, 159-169.

Axelsen, L. N., Stahlhut, M., Mohammed, S., et al. (2006). Identification of ischemiaregulated phosphorylation sites in connexin43: A possible target for the antiarrhythmic peptide analogue rotigaptide (ZP123). J Mol Cell Cardiol, 40, 790-798.

Banerjee, D., Das, S., Molina, S. A., et al. (2011). Investigation of the reciprocal relationship between the expression of two gap junction connexin proteins, connexin46 and connexin43. J Biol Chem, 286, 24519-24533.

Bao, X., Reuss, L., and Altenberg, G. A. (2004). Regulation of purified and reconstituted connexin 43 hemichannels by protein kinase C-mediated phosphorylation of Serine 368. J Biol Chem, 279, 20058-20066.

Baranova, A., Ivanov, D., Petrash, N., et al. (2004). The mammalian pannexin family is homologous to the invertebrate innexin gap junction proteins. Genomics, 83, 706-716.

Barbe, M. T., Monyer, H., and Bruzzone, R. (2006). Cell-cell communication beyond connexins: the pannexin channels. Physiology (Bethesda), 21, 103-114.

Bargiotas, P., Krenz, A., Hormuzdi, S. G., et al. (2011). Pannexins in ischemia-induced neurodegeneration. Proc Natl Acad Sci U S A, 108, 20772-20777.

Baruch, A., Greenbaum, D., Levy, E. T., et al. (2001). Defining a link between gap junction communication, proteolysis, and cataract formation. J Biol Chem, 276, 28999-29006.

Bates, D. C., Sin, W. C., Aftab, Q., and Naus, C. C. (2007). Connexin43 enhances glioma invasion by a mechanism involving the carboxy terminus. Glia, 55, 1554-1564.

Beardslee, M. A., Lerner, D. L., Tadros, P. N., et al. (2000). Dephosphorylation and intracellular redistribution of ventricular connexin43 during electrical uncoupling induced by ischemia. Circ Res, 87, 656-662.

Bejarano, E., Girao, H., Yuste, A., et al. (2012). Autophagy modulates dynamics of connexins at the plasma membrane in a ubiquitin-dependent manner. Mol Biol Cell, 23, 2156-2169.

Bellei, B., Mastrofrancesco, A., Briganti, S., et al. (2008). Ultraviolet A induced modulation of gap junctional intercellular communication by P38 MAPK activation in human keratinocytes. Exp Dermatol, 17, 115-124.

Berthoud, V. M., Beyer, E. C., Kurata, W. E., Lau, A. F., and Lampe, P. D. (1997). The gapjunction protein connexin 56 is phosphorylated in the intracellular loop and the carboxy-terminal region. Eur J Biochem, 244, 89-97. 
Bhalla-Gehi, R., Penuela, S., Churko, J. M., Shao, Q., and Laird, D. W. (2010). Pannexin1 and pannexin3 delivery, cell surface dynamics, and cytoskeletal interactions. J Biol Chem, 285, 9147-9160.

Boassa, D., Ambrosi, C., Qiu, F., Dahl, G., Gaietta, G., and Sosinsky, G. (2007). Pannexin1 channels contain a glycosylation site that targets the hexamer to the plasma membrane. J Biol Chem, 282, 31733-31743.

Boassa, D., Qiu, F., Dahl, G., and Sosinsky, G. (2008). Trafficking dynamics of glycosylated pannexin 1 proteins. Cell Commun Adhes, 15, 119-132.

Brill, L. M., Xiong, W., Lee, K. B., et al. (2009). Phosphoproteomic analysis of human embryonic stem cells. Cell Stem Cell, 5, 204-213.

Britz-Cunningham, S. H., Shah, M. M., Zuppan, C. W., and Fletcher, W. H. (1995). Mutations of the Connexin43 gap-junction gene in patients with heart malformations and defects of laterality. N Engl J Med, 332, 1323-1329.

Bruzzone, R., Barbe, M. T., Jakob, N. J., and Monyer, H. (2005). Pharmacological properties of homomeric and heteromeric pannexin hemichannels expressed in Xenopus oocytes. J Neurochem, 92, 1033-1043.

Bruzzone, R., Hormuzdi, S. G., Barbe, M. T., Herb, A., and Monyer, H. (2003). Pannexins, a family of gap junction proteins expressed in brain. Proc Natl Acad Sci U S A, $100,13644-13649$.

Bruzzone, R., White, T. W., and Paul, D. L. (1996). Connections with connexins: the molecular basis of direct intercellular signaling. Eur J Biochem, 238, 1-27.

Bunse, S., Schmidt, M., Hoffmann, S., Engelhardt, K., Zoidl, G., and Dermietzel, R. (2011). Single cysteines in the extracellular and transmembrane regions modulate pannexin 1 channel function. J Membr Biol, 244, 21-33.

Bunse, S., Schmidt, M., Prochnow, N., Zoidl, G., and Dermietzel, R. (2010). Intracellular cysteine 346 is essentially involved in regulating Panx1 channel activity. J Biol Chem, 285, 38444-38452.

Chanson, M., White, M. M., and Garber, S. S. (1996). cAMP promotes gap junctional coupling in T84 cells. Am J Physiol, 271, C533-539.

Chekeni, F. B., Elliott, M. R., Sandilos, J. K., et al. (2010). Pannexin 1 channels mediate 'find-me' signal release and membrane permeability during apoptosis. Nature, 467, 863-867.

Chen, J., Pan, L., Wei, Z., Zhao, Y., and Zhang, M. (2008). Domain-swapped dimerization of Z0-1 PDZ2 generates specific and regulatory connexin43-binding sites. EMBO J, 27, 2113-2123.

Chen, V. C., Gouw, J. W., Naus, C. C., and Foster, L. J. (2012). Connexin multi-site phosphorylation: Mass spectrometry-based proteomics fills the gap. Biochim Biophys Acta.

Chen, Y., Deng, Y., Bao, X., Reuss, L., and Altenberg, G. A. (2005). Mechanism of the defect in gap-junctional communication by expression of a connexin 26 mutant associated with dominant deafness. FASEB J, 19, 1516-1518.

Ciesla, J., Fraczyk, T., and Rode, W. (2011). Phosphorylation of basic amino acid residues in proteins: important but easily missed. Acta Biochim Pol, 58, 137148.

Colomer, J., and Means, A. R. (2007). Physiological roles of the Ca2+/CaM-dependent protein kinase cascade in health and disease. Subcell Biochem, 45, 169-214.

Colussi, C., Rosati, J., Straino, S., et al. (2011). Nepsilon-lysine acetylation determines dissociation from GAP junctions and lateralization of connexin 43 in normal and dystrophic heart. Proc Natl Acad Sci U S A, 108, 2795-2800. 
Cooper, C. D., and Lampe, P. D. (2002). Casein kinase 1 regulates connexin-43 gap junction assembly. J Biol Chem, 277, 44962-44968.

Cooper, C. D., Solan, J. L., Dolejsi, M. K., and Lampe, P. D. (2000). Analysis of connexin phosphorylation sites. Methods, 20, 196-204.

Cottrell, G. T., Lin, R., Warn-Cramer, B. J., Lau, A. F., and Burt, J. M. (2003). Mechanism of $\mathrm{v}$-Src- and mitogen-activated protein kinase-induced reduction of gap junction communication. Am J Physiol Cell Physiol, 284, C511-520.

Crespin, S., Bechberger, J., Mesnil, M., Naus, C. C., and Sin, W. C. (2010). The carboxyterminal tail of connexin43 gap junction protein is sufficient to mediate cytoskeleton changes in human glioma cells. J Cell Biochem, 110, 589-597.

D'hondt, C., Ponsaerts, R., De Smedt, H., Bultynck, G., and Himpens, B. (2009). Pannexins, distant relatives of the connexin family with specific cellular functions? Bioessays, 31, 953-974.

D'hondt, C., Ponsaerts, R., De Smedt, H., et al. (2010). Pannexin channels in ATP release and beyond: an unexpected rendezvous at the endoplasmic reticulum. Cell Signal, 23, 305-316.

Dang, X., Doble, B. W., and Kardami, E. (2003). The carboxy-tail of connexin-43 localizes to the nucleus and inhibits cell growth. Mol Cell Biochem, 242, 35-38.

Dang, X., Jeyaraman, M., and Kardami, E. (2006). Regulation of connexin-43-mediated growth inhibition by a phosphorylatable amino-acid is independent of gap junction-forming ability. Mol Cell Biochem, 289, 201-207.

Davis, F. P. (2011). Phosphorylation at the interface. Structure, 19, 1726-1727.

De Vuyst, E., Decrock, E., Cabooter, L., et al. (2006). Intracellular calcium changes trigger connexin 32 hemichannel opening. EMBO J, 25, 34-44.

De Vuyst, E., Decrock, E., De Bock, M., et al. (2007). Connexin hemichannels and gap junction channels are differentially influenced by lipopolysaccharide and basic fibroblast growth factor. Mol Biol Cell, 18, 34-46.

De Vuyst, E., Wang, N., Decrock, E., et al. (2009). Ca(2+) regulation of connexin 43 hemichannels in C6 glioma and glial cells. Cell Calcium, 46, 176-187.

de Zwart-Storm, E. A., van Geel, M., van Neer, P. A., Steijlen, P. M., Martin, P. E., and van Steensel, M. A. (2008). A novel missense mutation in the second extracellular domain of GJB2, p.Ser183Phe, causes a syndrome of focal palmoplantar keratoderma with deafness. Am J Pathol, 173, 1113-1119.

Deng, Y., Chen, Y., Reuss, L., and Altenberg, G. A. (2006). Mutations of connexin 26 at position 75 and dominant deafness: essential role of arginine for the generation of functional gap-junctional channels. Hear Res, 220, 87-94.

DeRosa, A. M., Mui, R., Srinivas, M., and White, T. W. (2006). Functional characterization of a naturally occurring Cx50 truncation. Invest Ophthalmol Vis Sci, 47, 4474-4481.

Diestel, S., Eckert, R., Hulser, D., and Traub, O. (2004). Exchange of serine residues 263 and 266 reduces the function of mouse gap junction protein connexin 31 and exhibits a dominant-negative effect on the wild-type protein in HeLa cells. Exp Cell Res, 294, 446-457.

Diez, J. A., Elvira, M., and Villalobo, A. (1995). Phosphorylation of connexin-32 by the epidermal growth factor receptor tyrosine kinase. Ann N Y Acad Sci, 766, 477480.

Doble, B. W., Chen, Y., Bosc, D. G., Litchfield, D. W., and Kardami, E. (1996). Fibroblast growth factor-2 decreases metabolic coupling and stimulates phosphorylation 
as well as masking of connexin43 epitopes in cardiac myocytes. Circ Res, 79, 647-658.

Doble, B. W., Dang, X., Ping, P., et al. (2004). Phosphorylation of serine 262 in the gap junction protein connexin-43 regulates DNA synthesis in cell-cell contact forming cardiomyocytes. J Cell Sci, 117, 507-514.

Doble, B. W., Ping, P., and Kardami, E. (2000). The epsilon subtype of protein kinase C is required for cardiomyocyte connexin-43 phosphorylation. Circ Res, 86, 293301.

Donaldson, J. G., Finazzi, D., and Klausner, R. D. (1992). Brefeldin A inhibits Golgi membrane-catalysed exchange of guanine nucleotide onto ARF protein. Nature, 360, 350-352.

Dunn, C. A., Su, V., Lau, A. F., and Lampe, P. D. (2011). Activation of Akt, not connexin 43 protein ubiquitination, regulates gap junction stability. J Biol Chem, 287, 2600-2607.

Dvoriantchikova, G., Ivanov, D., Panchin, Y., and Shestopalov, V. I. (2006). Expression of pannexin family of proteins in the retina. FEBS Lett, 580, 2178-2182.

Ek-Vitorin, J. F., King, T. J., Heyman, N. S., Lampe, P. D., and Burt, J. M. (2006). Selectivity of connexin 43 channels is regulated through protein kinase Cdependent phosphorylation. Circ Res, 98, 1498-1505.

Evans, W. H., Bultynck, G., and Leybaert, L. (2012). Manipulating Connexin Communication Channels: Use of Peptidomimetics and the Translational Outputs. J Membr Biol.

Faigle, M., Seessle, J., Zug, S., El Kasmi, K. C., and Eltzschig, H. K. (2008). ATP release from vascular endothelia occurs across $\mathrm{Cx} 43$ hemichannels and is attenuated during hypoxia. PLoS One, 3, e2801.

Fong, J., Kells, R., Gumpert, A., Marzillier, J., Davidson, M., and Falk, M. (2012). Internalized gap junctions are degraded by autophagy. Autophagy, 8, 794-811.

Gehi, R., Shao, Q., and Laird, D. W. (2011). Pathways regulating the trafficking and turnover of pannexin 1 protein and the role of the C-terminal domain. J Biol Chem, 286, 27639-27653.

Geiss-Friedlander, R., and Melchior, F. (2007). Concepts in sumoylation: a decade on. Nat Rev Mol Cell Biol, 8, 947-956.

Giepmans, B. N. (2004). Gap junctions and connexin-interacting proteins. Cardiovasc Res, 62, 233-245.

Giepmans, B. N., Hengeveld, T., Postma, F. R., and Moolenaar, W. H. (2001). Interaction of c-Src with gap junction protein connexin-43. Role in the regulation of cellcell communication. J Biol Chem, 276, 8544-8549.

Gomez, L. A., Monette, J. S., Chavez, J. D., Maier, C. S., and Hagen, T. M. (2009). Supercomplexes of the mitochondrial electron transport chain decline in the aging rat heart. Arch Biochem Biophys, 490, 30-35.

Gong, X., Cheng, C., and Xia, C. H. (2007). Connexins in lens development and cataractogenesis. J Membr Biol, 218, 9-12.

Gong, X., Li, E., Klier, G., et al. (1997). Disruption of alpha3 connexin gene leads to proteolysis and cataractogenesis in mice. Cell, 91, 833-843.

Grotenbreg, G., and Ploegh, H. (2007). Chemical biology: dressed-up proteins. Nature, 446, 993-995.

Guo, A., Villen, J., Kornhauser, J., et al. (2008). Signaling networks assembled by oncogenic EGFR and c-Met. Proc Natl Acad Sci U S A, 105, 692-697. 
Hertlein, B., Butterweck, A., Haubrich, S., Willecke, K., and Traub, O. (1998). Phosphorylated carboxy terminal serine residues stabilize the mouse gap junction protein connexin45 against degradation. J Membr Biol, 162, 247-257.

Herve, J. C., Derangeon, M., Sarrouilhe, D., Giepmans, B. N., and Bourmeyster, N. (2012). Gap junctional channels are parts of multiprotein complexes. Biochim Biophys Acta, 1818, 1844-1865.

Huang, P. H., Mukasa, A., Bonavia, R., et al. (2007). Quantitative analysis of EGFRvIII cellular signaling networks reveals a combinatorial therapeutic strategy for glioblastoma. Proc Natl Acad Sci U S A, 104, 12867-12872.

Huang, R. Y., Laing, J. G., Kanter, E. M., et al. (2011). Identification of CaMKII phosphorylation sites in Connexin43 by high-resolution mass spectrometry. J Proteome Res, 10, 1098-1109.

Huang, Y., Sirkowski, E. E., Stickney, J. T., and Scherer, S. S. (2005). Prenylationdefective human connexin32 mutants are normally localized and function equivalently to wild-type connexin32 in myelinating Schwann cells. J Neurosci, 25, 7111-7120.

Hunter, A. W., Barker, R. J., Zhu, C., and Gourdie, R. G. (2005). Zonula occludens-1 alters connexin43 gap junction size and organization by influencing channel accretion. Mol Biol Cell, 16, 5686-5698.

Huttlin, E. L., Jedrychowski, M. P., Elias, J. E., et al. (2010). A tissue-specific atlas of mouse protein phosphorylation and expression. Cell, 143, 1174-1189.

Iacobas, D. A., Urban-Maldonado, M., Iacobas, S., Scemes, E., and Spray, D. C. (2003). Array analysis of gene expression in connexin-43 null astrocytes. Physiol Genomics, 15, 177-190.

Ishikawa, M., Iwamoto, T., Nakamura, T., Doyle, A., Fukumoto, S., and Yamada, Y. (2011). Pannexin 3 functions as an ER $\mathrm{Ca}(2+)$ channel, hemichannel, and gap junction to promote osteoblast differentiation. J Cell Biol, 193, 1257-1274.

Iusem, N. D., De Larminat, M. A., Tezon, J. G., Blaquier, J. A., and Belocopitow, E. (1984). Androgen dependence of protein $\mathrm{N}$-glycosylation in rat epididymis. Endocrinology, 114, 1448-1453.

Jacobs, M. D., Soeller, C., Sisley, A. M., Cannell, M. B., and Donaldson, P. J. (2004). Gap junction processing and redistribution revealed by quantitative optical measurements of connexin46 epitopes in the lens. Invest Ophthalmol Vis Sci, 45, 191-199.

Jeyaraman, M. M., Srisakuldee, W., Nickel, B. E., and Kardami, E. (2011). Connexin43 phosphorylation and cytoprotection in the heart. Biochim Biophys Acta, 1818, 2009-2013.

Jiang, J. X. (2010). Gap junctions or hemichannel-dependent and independent roles of connexins in cataractogenesis and lens development. Curr Mol Med, 10, 851863.

Jiang, J. X., Paul, D. L., and Goodenough, D. A. (1993). Posttranslational phosphorylation of lens fiber connexin46: a slow occurrence. Invest Ophthalmol Vis Sci, 34, 3558-3565.

Jin, C., Martyn, K. D., Kurata, W. E., Warn-Cramer, B. J., and Lau, A. F. (2004). Connexin43 PDZ2 binding domain mutants create functional gap junctions and exhibit altered phosphorylation. Cell Commun Adhes, 11, 67-87.

Johnson, R. G., Reynhout, J. K., TenBroek, E. M., et al. (2012). Gap junction assembly: roles for the formation plaque and regulation by the $\mathrm{C}$-terminus of connexin 43. Mol Biol Cell, 23, 71-86. 
Johnstone, S. R., Billaud, M., Lohman, A. W., Taddeo, E. P., and Isakson, B. E. (2012). Posttranslational modifications in connexins and pannexins. J Membr Biol, 245, 319-332.

Johnstone, S. R., Ross, J., Rizzo, M. J., et al. (2009). Oxidized phospholipid species promote in vivo differential cx43 phosphorylation and vascular smooth muscle cell proliferation. Am J Pathol, 175, 916-924.

Joshi-Mukherjee, R., Coombs, W., Burrer, C., de Mora, I. A., Delmar, M., and Taffet, S. M. (2007). Evidence for the presence of a free C-terminal fragment of cx43 in cultured cells. Cell Commun Adhes, 14, 75-84.

Kalcheva, N., Qu, J., Sandeep, N., et al. (2007). Gap junction remodeling and cardiac arrhythmogenesis in a murine model of oculodentodigital dysplasia. Proc Natl Acad Sci U S A, 104, 20512-20516.

Kameritsch, P., Khandoga, N., Nagel, W., Hundhausen, C., Lidington, D., and Pohl, U. (2005). Nitric oxide specifically reduces the permeability of Cx37-containing gap junctions to small molecules. J Cell Physiol, 203, 233-242.

Kanemitsu, M. Y., Jiang, W., and Eckhart, W. (1998). Cdc2-mediated phosphorylation of the gap junction protein, connexin43, during mitosis. Cell Growth Differ, 9, 1321.

Kar, R., Batra, N., Riquelme, M. A., and Jiang, J. X. (2012). Biological role of connexin intercellular channels and hemichannels. Arch Biochem Biophys, 524, 2-15.

Kee, J. M., and Muir, T. W. (2012). Chasing phosphohistidine, an elusive sibling in the phosphoamino acid family. ACS Chem Biol, 7, 44-51.

Kemp, B. E., and Pearson, R. B. (1990). Protein kinase recognition sequence motifs. Trends Biochem Sci, 15, 342-346.

Kennelly, P. J., and Krebs, E. G. (1991). Consensus sequences as substrate specificity determinants for protein kinases and protein phosphatases. J Biol Chem, 266, $15555-15558$.

Kim, D. Y., Kam, Y., Koo, S. K., and Joe, C. O. (1999). Gating connexin 43 channels reconstituted in lipid vesicles by mitogen-activated protein kinase phosphorylation. J Biol Chem, 274, 5581-5587.

Kim, W., Bennett, E. J., Huttlin, E. L., et al. (2011). Systematic and quantitative assessment of the ubiquitin-modified proteome. Mol Cell, 44, 325-340.

Kjenseth, A., Fykerud, T. A., Sirnes, S., et al. (2012). The gap junction channel protein connexin 43 is covalently modified and regulated by SUMOylation. J Biol Chem, 287, 15851-15861.

Kothmann, W. W., Li, X., Burr, G. S., and O'Brien, J. (2007). Connexin 35/36 is phosphorylated at regulatory sites in the retina. Vis Neurosci, 24, 363-375.

Kothmann, W. W., Massey, S. C., and O'Brien, J. (2009). Dopamine-stimulated dephosphorylation of connexin 36 mediates AII amacrine cell uncoupling. J Neurosci, 29, 14903-14911.

Laird, D. W. (2005). Connexin phosphorylation as a regulatory event linked to gap junction internalization and degradation. Biochim Biophys Acta, 1711, 172182.

Lampe, P. D., Cooper, C. D., King, T. J., and Burt, J. M. (2006). Analysis of Connexin43 phosphorylated at S325, S328 and S330 in normoxic and ischemic heart. J Cell Sci, 119, 3435-3442.

Lampe, P. D., Kurata, W. E., Warn-Cramer, B. J., and Lau, A. F. (1998). Formation of a distinct connexin 43 phosphoisoform in mitotic cells is dependent upon p34cdc2 kinase. J Cell Sci, 111 ( Pt 6), 833-841. 
Lampe, P. D., and Lau, A. F. (2000). Regulation of gap junctions by phosphorylation of connexins. Arch Biochem Biophys, 384, 205-215.

Lampe, P. D., and Lau, A. F. (2004). The effects of connexin phosphorylation on gap junctional communication. Int J Biochem Cell Biol, 36, 1171-1186.

Lampe, P. D., TenBroek, E. M., Burt, J. M., Kurata, W. E., Johnson, R. G., and Lau, A. F. (2000). Phosphorylation of connexin43 on serine368 by protein kinase $\mathrm{C}$ regulates gap junctional communication. J Cell Biol, 149, 1503-1512.

Larsen, M. R., Trelle, M. B., Thingholm, T. E., and Jensen, O. N. (2006). Analysis of posttranslational modifications of proteins by tandem mass spectrometry. Biotechniques, 40, 790-798.

Lee, T. Y., Huang, H. D., Hung, J. H., Huang, H. Y., Yang, Y. S., and Wang, T. H. (2006). dbPTM: an information repository of protein post-translational modification. Nucleic Acids Res, 34, D622-627.

Leithe, E., and Rivedal, E. (2007). Ubiquitination of gap junction proteins. J Membr Biol, 217, 43-51.

Li, J., Cheng, L., Wang, L. J., et al. (2010). Cell surface sialic acid inhibits Cx43 gap junction functions in constructed Hela cancer cells involving in sialylated Ncadherin. Mol Cell Biochem, 344, 241-251.

Lichtenstein, A., Minogue, P. J., Beyer, E. C., and Berthoud, V. M. (2011). Autophagy: a pathway that contributes to connexin degradation. J Cell Sci, 124, 910-920.

Lin, D., Lobell, S., Jewell, A., and Takemoto, D. J. (2004). Differential phosphorylation of connexin 46 and connexin 50 by $\mathrm{H} 2 \mathrm{O} 2$ activation of protein kinase Cgamma. Mol Vis, 10, 688-695.

Lin, J. S., Fitzgerald, S., Dong, Y., Knight, C., Donaldson, P., and Kistler, J. (1997). Processing of the gap junction protein connexin50 in the ocular lens is accomplished by calpain. Eur J Cell Biol, 73, 141-149.

Lin, R., Warn-Cramer, B. J., Kurata, W. E., and Lau, A. F. (2001). v-Src phosphorylation of connexin 43 on Tyr247 and Tyr265 disrupts gap junctional communication. J Cell Biol, 154, 815-827.

Linder, M. E., and Deschenes, R. J. (2003). New insights into the mechanisms of protein palmitoylation. Biochemistry, 42, 4311-4320.

Liu, J., Ek Vitorin, J. F., Weintraub, S. T., et al. (2011). Phosphorylation of connexin 50 by protein kinase A enhances gap junction and hemichannel function. J Biol Chem, 286, 16914-16928.

Locke, D., Bian, S., Li, H., and Harris, A. L. (2009). Post-translational modifications of connexin26 revealed by mass spectrometry. Biochem J, 424, 385-398.

Locke, D., Koreen, I. V., and Harris, A. L. (2006). Isoelectric points and posttranslational modifications of connexin26 and connexin32. FASEB J, 20, 12211223.

Locke, D., Liu, J., and Harris, A. L. (2005). Lipid rafts prepared by different methods contain different connexin channels, but gap junctions are not lipid rafts. Biochemistry, 44, 13027-13042.

Lurtz, M. M., and Louis, C. F. (2007). Purinergic receptor-mediated regulation of lens connexin43. Invest Ophthalmol Vis Sci, 48, 4177-4186.

Maeda, S., Nakagawa, S., Suga, M., et al. (2009). Structure of the connexin 26 gap junction channel at 3.5 A resolution. Nature, 458, 597-602.

Malone, P., Miao, H., Parker, A., Juarez, S., and Hernandez, M. R. (2007). Pressure induces loss of gap junction communication and redistribution of connexin 43 in astrocytes. Glia, 55, 1085-1098. 
Manthey, D., Banach, K., Desplantez, T., et al. (2001). Intracellular domains of mouse connexin26 and -30 affect diffusional and electrical properties of gap junction channels. J Membr Biol, 181, 137-148.

Marchi, S., Marinello, M., Bononi, A., et al. (2012). Selective modulation of subtype III IP(3)R by Akt regulates ER Ca(2)(+) release and apoptosis. Cell Death Dis, 3, e304.

Marquez-Rosado, L., Solan, J. L., Dunn, C. A., Norris, R. P., and Lampe, P. D. (2011). Connexin43 phosphorylation in brain, cardiac, endothelial and epithelial tissues. Biochim Biophys Acta, 1818, 1985-1992.

Martinez, A. D., Hayrapetyan, V., Moreno, A. P., and Beyer, E. C. (2003). A carboxyl terminal domain of connexin43 is critical for gap junction plaque formation but not for homo- or hetero-oligomerization. Cell Commun Adhes, 10, 323-328.

McKinnon, R. L., Bolon, M. L., Wang, H. X., et al. (2009). Reduction of electrical coupling between microvascular endothelial cells by NO depends on connexin37. Am J Physiol Heart Circ Physiol, 297, H93-H101.

Miura, T., Yano, T., Naitoh, K., et al. (2007). Delta-opioid receptor activation before ischemia reduces gap junction permeability in ischemic myocardium by PKCepsilon-mediated phosphorylation of connexin 43. Am J Physiol Heart Circ Physiol, 293, H1425-1431.

Moorby, C. D. (2000). A connexin 43 mutant lacking the carboxyl cytoplasmic domain inhibits both growth and motility of mouse 3T3 fibroblasts. Mol Carcinog, 28, 23-30.

Morel, S., Burnier, L., Roatti, A., et al. (2010). Unexpected role for the human Cx37 C1019T polymorphism in tumour cell proliferation. Carcinogenesis, 31, 19221931.

Morley, G. E., Ek-Vitorin, J. F., Taffet, S. M., and Delmar, M. (1997). Structure of connexin43 and its regulation by pHi. J Cardiovasc Electrophysiol, 8, 939-951.

Morrison, R. S., Kinoshita, Y., Johnson, M. D., et al. (2002). Proteomic analysis in the neurosciences. Mol Cell Proteomics, 1, 553-560.

Munton, R. P., Tweedie-Cullen, R., Livingstone-Zatchej, M., et al. (2007). Qualitative and quantitative analyses of protein phosphorylation in naive and stimulated mouse synaptosomal preparations. Mol Cell Proteomics, 6, 283-293.

Musil, L. S., Beyer, E. C., and Goodenough, D. A. (1990). Expression of the gap junction protein connexin43 in embryonic chick lens: molecular cloning, ultrastructural localization, and post-translational phosphorylation. J Membr Biol, 116, 163175.

Nishi, H., Hashimoto, K., and Panchenko, A. R. (2011). Phosphorylation in proteinprotein binding: effect on stability and function. Structure, 19, 1807-1815.

Norris, R. P., Freudzon, M., Mehlmann, L. M., et al. (2008). Luteinizing hormone causes MAP kinase-dependent phosphorylation and closure of connexin 43 gap junctions in mouse ovarian follicles: one of two paths to meiotic resumption. Development, 135, 3229-3238.

O'Quinn, M. P., Palatinus, J. A., Harris, B. S., Hewett, K. W., and Gourdie, R. G. (2011). A peptide mimetic of the connexin 43 carboxyl terminus reduces gap junction remodeling and induced arrhythmia following ventricular injury. Circ Res, 108, 704-715.

Oh, S., Abrams, C. K., Verselis, V. K., and Bargiello, T. A. (2000). Stoichiometry of transjunctional voltage-gating polarity reversal by a negative charge 
substitution in the amino terminus of a connexin32 chimera. J Gen Physiol, 116, 13-31.

Oh, S., Rivkin, S., Tang, Q., Verselis, V. K., and Bargiello, T. A. (2004). Determinants of gating polarity of a connexin 32 hemichannel. Biophys J, 87, 912-928.

Oh, S., Rubin, J. B., Bennett, M. V., Verselis, V. K., and Bargiello, T. A. (1999). Molecular determinants of electrical rectification of single channel conductance in gap junctions formed by connexins 26 and 32. J Gen Physiol, 114, 339-364.

Oshima, A., Tani, K., Hiroaki, Y., Fujiyoshi, Y., and Sosinsky, G. E. (2007). Threedimensional structure of a human connexin26 gap junction channel reveals a plug in the vestibule. Proc Natl Acad Sci U S A, 104, 10034-10039.

Palacios-Prado, N., and Bukauskas, F. F. (2011). Modulation of metabolic communication through gap junction channels by transjunctional voltage; synergistic and antagonistic effects of gating and ionophoresis. Biochim Biophys Acta, 1818, 1884-1894.

Palatinus, J. A., Rhett, J. M., and Gourdie, R. G. (2011a). The connexin43 carboxyl terminus and cardiac gap junction organization. Biochim Biophys Acta, 1818, 1831-1843.

Palatinus, J. A., Rhett, J. M., and Gourdie, R. G. (2011b). Enhanced PKCepsilon mediated phosphorylation of connexin 43 at serine 368 by a carboxyl-terminal mimetic peptide is dependent on injury. Channels (Austin), 5, 236-240.

Papeleu, P., Vanhaecke, T., Elaut, G., et al. (2005). Differential effects of histone deacetylase inhibitors in tumor and normal cells-what is the toxicological relevance? Crit Rev Toxicol, 35, 363-378.

Park, D. J., Wallick, C. J., Martyn, K. D., Lau, A. F., Jin, C., and Warn-Cramer, B. J. (2007). Akt phosphorylates Connexin43 on Ser373, a "mode-1" binding site for 14-3-3. Cell Commun Adhes, 14, 211-226.

Park, H. J., Hahn, S. H., Chun, Y. M., Park, K., and Kim, H. N. (2000). Connexin26 mutations associated with nonsyndromic hearing loss. Laryngoscope, 110, 1535-1538.

Patel, L. S., Mitchell, C. K., Dubinsky, W. P., and O'Brien, J. (2006). Regulation of gap junction coupling through the neuronal connexin Cx35 by nitric oxide and cGMP. Cell Commun Adhes, 13, 41-54.

Paul, D. L., Ebihara, L., Takemoto, L. J., Swenson, K. I., and Goodenough, D. A. (1991). Connexin46, a novel lens gap junction protein, induces voltage-gated currents in nonjunctional plasma membrane of Xenopus oocytes. J Cell Biol, 115, 10771089.

Paulson, A. F., Lampe, P. D., Meyer, R. A., et al. (2000). Cyclic AMP and LDL trigger a rapid enhancement in gap junction assembly through a stimulation of connexin trafficking. J Cell Sci, 113 ( Pt 17), 3037-3049.

Penuela, S., Bhalla, R., Gong, X. Q., et al. (2007). Pannexin 1 and pannexin 3 are glycoproteins that exhibit many distinct characteristics from the connexin family of gap junction proteins. J Cell Sci, 120, 3772-3783.

Penuela, S., Bhalla, R., Nag, K., and Laird, D. W. (2009). Glycosylation regulates pannexin intermixing and cellular localization. Mol Biol Cell, 20, 4313-4323.

Penuela, S., Celetti, S. J., Bhalla, R., Shao, Q., and Laird, D. W. (2008). Diverse subcellular distribution profiles of pannexin 1 and pannexin 3. Cell Commun Adhes, 15, 133-142.

Phelan, P., Bacon, J. P., Davies, J. A., et al. (1998). Innexins: a family of invertebrate gapjunction proteins. Trends Genet, 14, 348-349. 
Ponsaerts, R., De Vuyst, E., Retamal, M., et al. (2010). Intramolecular loop/tail interactions are essential for connexin 43-hemichannel activity. FASEB J, 24, 4378-4395.

Ponsaerts, R., Wang, N., Himpens, B., Leybaert, L., and Bultynck, G. (2012). The contractile system as a negative regulator of the connexin 43 hemichannel. Biol Cell, 104, 367-377.

Prochnow, N., Hoffmann, S., Vroman, R., et al. (2009). Pannexin1 in the outer retina of the zebrafish, Danio rerio. Neuroscience, 162, 1039-1054.

Procida, K., Jorgensen, L., Schmitt, N., et al. (2009). Phosphorylation of connexin43 on serine 306 regulates electrical coupling. Heart Rhythm, 6, 1632-1638.

Purnick, P. E., Benjamin, D. C., Verselis, V. K., Bargiello, T. A., and Dowd, T. L. (2000). Structure of the amino terminus of a gap junction protein. Arch Biochem Biophys, 381, 181-190.

Purnick, P. E., Oh, S., Abrams, C. K., Verselis, V. K., and Bargiello, T. A. (2000). Reversal of the gating polarity of gap junctions by negative charge substitutions in the N-terminus of connexin 32. Biophys J, 79, 2403-2415.

Rahman, S., Carlile, G., and Evans, W. H. (1993). Assembly of hepatic gap junctions. Topography and distribution of connexin 32 in intracellular and plasma membranes determined using sequence-specific antibodies. J Biol Chem, 268, 1260-1265.

Rao, G. N., Gutekunst, K. A., and Church, R. L. (1990). Bovine lens membrane proteins: MP70, MP64, and MP38 are products of the same gene. Ophthalmic Res, 22, 166-172.

Remo, B. F., Qu, J., Volpicelli, F. M., et al. (2011). Phosphatase-resistant gap junctions inhibit pathological remodeling and prevent arrhythmias. Circ Res, 108, 14591466.

Retamal, M. A., Cortes, C. J., Reuss, L., Bennett, M. V., and Saez, J. C. (2006). Snitrosylation and permeation through connexin 43 hemichannels in astrocytes: induction by oxidant stress and reversal by reducing agents. Proc Natl Acad Sci U S A, 103, 4475-4480.

Retamal, M. A., Schalper, K. A., Shoji, K. F., Bennett, M. V., and Saez, J. C. (2007). Opening of connexin 43 hemichannels is increased by lowering intracellular redox potential. Proc Natl Acad Sci U S A, 104, 8322-8327.

Retamal, M. A., Yin, S., Altenberg, G. A., and Reuss, L. (2009). Modulation of Cx46 hemichannels by nitric oxide. Am J Physiol Cell Physiol, 296, C1356-1363.

Rhett, J. M., and Gourdie, R. G. (2012). The perinexus: a new feature of Cx43 gap junction organization. Heart Rhythm, 9, 619-623.

Richard, G., White, T. W., Smith, L. E., et al. (1998). Functional defects of Cx26 resulting from a heterozygous missense mutation in a family with dominant deafmutism and palmoplantar keratoderma. Hum Genet, 103, 393-399.

Richards, T. S., Dunn, C. A., Carter, W. G., Usui, M. L., Olerud, J. E., and Lampe, P. D. (2004). Protein kinase $C$ spatially and temporally regulates gap junctional communication during human wound repair via phosphorylation of connexin43 on serine368. J Cell Biol, 167, 555-562.

Rigbolt, K. T., Prokhorova, T. A., Akimov, V., et al. (2011). System-wide temporal characterization of the proteome and phosphoproteome of human embryonic stem cell differentiation. Sci Signal, 4, rs3.

Rikova, K., Guo, A., Zeng, Q., et al. (2007). Global survey of phosphotyrosine signaling identifies oncogenic kinases in lung cancer. Cell, 131, 1190-1203. 
Saez, J. C., Berthoud, V. M., Branes, M. C., Martinez, A. D., and Beyer, E. C. (2003). Plasma membrane channels formed by connexins: their regulation and functions. Physiol Rev, 83, 1359-1400.

Saez, J. C., Martinez, A. D., Branes, M. C., and Gonzalez, H. E. (1998). Regulation of gap junctions by protein phosphorylation. Braz J Med Biol Res, 31, 593-600.

Saez, J. C., Nairn, A. C., Czernik, A. J., Fishman, G. I., Spray, D. C., and Hertzberg, E. L. (1997). Phosphorylation of connexin43 and the regulation of neonatal rat cardiac myocyte gap junctions. J Mol Cell Cardiol, 29, 2131-2145.

Saez, J. C., Nairn, A. C., Czernik, A. J., et al. (1990). Phosphorylation of connexin 32, a hepatocyte gap-junction protein, by cAMP-dependent protein kinase, protein kinase $\mathrm{C}$ and $\mathrm{Ca} 2+/$ calmodulin-dependent protein kinase II. Eur J Biochem, 192, 263-273.

Saez, J. C., Spray, D. C., Nairn, A. C., Hertzberg, E., Greengard, P., and Bennett, M. V. (1986). cAMP increases junctional conductance and stimulates phosphorylation of the 27-kDa principal gap junction polypeptide. Proc Natl Acad Sci U S A, 83, 2473-2477.

Saito, T., Krutovskikh, V., Marion, M. J., Ishak, K. G., Bennett, W. P., and Yamasaki, H. (2000). Human hemangiosarcomas have a common polymorphism but no mutations in the connexin37 gene. Int J Cancer, 86, 67-70.

Saleh, S. M., Takemoto, L. J., Zoukhri, D., and Takemoto, D. J. (2001). PKC-gamma phosphorylation of connexin 46 in the lens cortex. Mol Vis, 7, 240-246.

Sandilos, J. K., Chiu, Y. H., Chekeni, F. B., et al. (2012). Pannexin 1, an ATP release channel, is activated by caspase cleavage of its pore-associated $\mathrm{C}$ terminal autoinhibitory region. J Biol Chem.

Sato, T., Ohkusa, T., Honjo, H., et al. (2008). Altered expression of connexin43 contributes to the arrhythmogenic substrate during the development of heart failure in cardiomyopathic hamster. Am J Physiol Heart Circ Physiol, 294, H1164-1173.

Segretain, D., Fiorini, C., Decrouy, X., Defamie, N., Prat, J. R., and Pointis, G. (2004). A proposed role for ZO-1 in targeting connexin 43 gap junctions to the endocytic pathway. Biochimie, 86, 241-244.

Shah, M. M., Martinez, A. M., and Fletcher, W. H. (2002). The connexin43 gap junction protein is phosphorylated by protein kinase $A$ and protein kinase $\mathrm{C}$ : in vivo and in vitro studies. Mol Cell Biochem, 238, 57-68.

Shearer, D., Ens, W., Standing, K., and Valdimarsson, G. (2008). Posttranslational modifications in lens fiber connexins identified by off-line-HPLC MALDIquadrupole time-of-flight mass spectrometry. Invest Ophthalmol Vis Sci, 49, 1553-1562.

Shibayama, J., Lewandowski, R., Kieken, F., et al. (2006). Identification of a novel peptide that interferes with the chemical regulation of connexin43. Circ Res, 98, 1365-1372.

Siebert, A. P., Ma, Z., Grevet, J. D., Demuro, A., Parker, I., and Foskett, J. K. (2013). Structural and Functional Similarities of Calcium Homeostasis Modulator 1 (CALHM1) Ion Channel with Connexins, Pannexins, and Innexins. J Biol Chem, 288, 6140-6153.

Singh, D., Solan, J. L., Taffet, S. M., Javier, R., and Lampe, P. D. (2005). Connexin 43 interacts with zona occludens- 1 and -2 proteins in a cell cycle stage-specific manner. J Biol Chem, 280, 30416-30421. 
Singh, M. V., Swaminathan, P. D., Luczak, E. D., Kutschke, W., Weiss, R. M., and Anderson, M. E. (2012). MyD88 mediated inflammatory signaling leads to CaMKII oxidation, cardiac hypertrophy and death after myocardial infarction. J Mol Cell Cardiol, 52, 1135-1144.

Solan, J. L., Fry, M. D., TenBroek, E. M., and Lampe, P. D. (2003). Connexin43 phosphorylation at $\mathrm{S} 368$ is acute during $\mathrm{S}$ and $\mathrm{G} 2 / \mathrm{M}$ and in response to protein kinase C activation. J Cell Sci, 116, 2203-2211.

Solan, J. L., and Lampe, P. D. (2005). Connexin phosphorylation as a regulatory event linked to gap junction channel assembly. Biochim Biophys Acta, 1711, 154-163.

Solan, J. L., and Lampe, P. D. (2007). Key connexin 43 phosphorylation events regulate the gap junction life cycle. J Membr Biol, 217, 35-41.

Solan, J. L., and Lampe, P. D. (2008). Connexin 43 in LA-25 cells with active v-src is phosphorylated on Y247, Y265, S262, S279/282, and S368 via multiple signaling pathways. Cell Commun Adhes, 15, 75-84.

Solan, J. L., and Lampe, P. D. (2009). Connexin43 phosphorylation: structural changes and biological effects. Biochem J, 419, 261-272.

Sosinsky, G. E., Boassa, D., Dermietzel, R., et al. (2011). Pannexin channels are not gap junction hemichannels. Channels (Austin), 5, 193-197.

Srisakuldee, W., Jeyaraman, M. M., Nickel, B. E., Tanguy, S., Jiang, Z. S., and Kardami, E. (2009). Phosphorylation of connexin-43 at serine 262 promotes a cardiac injury-resistant state. Cardiovasc Res, 83, 672-681.

Stauch, K., Kieken, F., and Sorgen, P. (2012). Characterization of the structure and intermolecular interactions between the connexin 32 carboxyl-terminal domain and the protein partners synapse-associated protein 97 and calmodulin. J Biol Chem, 287, 27771-27788.

Stehberg, J., Moraga-Amaro, R., Salazar, C., et al. (2012). Release of gliotransmitters through astroglial connexin 43 hemichannels is necessary for fear memory consolidation in the basolateral amygdala. FASEB J, 26, 3649-3657.

Straub, A. C., Billaud, M., Johnstone, S. R., et al. (2011). Compartmentalized connexin 43 s-nitrosylation/denitrosylation regulates heterocellular communication in the vessel wall. Arterioscler Thromb Vasc Biol, 31, 399-407.

Straub, A. C., Johnstone, S. R., Heberlein, K. R., et al. (2009). Site-specific connexin phosphorylation is associated with reduced heterocellular communication between smooth muscle and endothelium. J Vasc Res, 47, 277-286.

Swayne, L. A., Sorbara, C. D., and Bennett, S. A. (2010). Pannexin 2 is expressed by postnatal hippocampal neural progenitors and modulates neuronal commitment. J Biol Chem, 285, 24977-24986.

Swenson, K. I., Piwnica-Worms, H., McNamee, H., and Paul, D. L. (1990). Tyrosine phosphorylation of the gap junction protein connexin43 is required for the pp60v-src-induced inhibition of communication. Cell Regul, 1, 989-1002.

Szado, T., Vanderheyden, V., Parys, J. B., et al. (2008). Phosphorylation of inositol 1,4,5trisphosphate receptors by protein kinase $\mathrm{B} /$ Akt inhibits $\mathrm{Ca} 2+$ release and apoptosis. Proc Natl Acad Sci U S A, 105, 2427-2432.

Takeda, A., Saheki, S., Shimazu, T., and Takeuchi, N. (1989). Phosphorylation of the 27$\mathrm{kDa}$ gap junction protein by protein kinase $\mathrm{C}$ in vitro and in rat hepatocytes. J Biochem, 106, 723-727.

Tang, Y., Liu, X., Zoltoski, R. K., et al. (2007). Age-related cataracts in alpha3Cx46knockout mice are dependent on a calpain 3 isoform. Invest Ophthalmol Vis Sci, 48, 2685-2694. 
Taruno, A., Vingtdeux, V., Ohmoto, M., et al. (2013). CALHM1 ion channel mediates purinergic neurotransmission of sweet, bitter and umami tastes. Nature, 495, 223-226.

TenBroek, E. M., Lampe, P. D., Solan, J. L., Reynhout, J. K., and Johnson, R. G. (2001). Ser364 of connexin43 and the upregulation of gap junction assembly by cAMP. J Cell Biol, 155, 1307-1318.

Thomas, T., Jordan, K., Simek, J., et al. (2005). Mechanisms of Cx43 and Cx26 transport to the plasma membrane and gap junction regeneration. J Cell Sci, 118, 44514462.

Toyofuku, T., Akamatsu, Y., Zhang, H., Kuzuya, T., Tada, M., and Hori, M. (2001). c-Src regulates the interaction between connexin-43 and ZO-1 in cardiac myocytes. J Biol Chem, 276, 1780-1788.

Toyofuku, T., Yabuki, M., Otsu, K., Kuzuya, T., Hori, M., and Tada, M. (1998). Direct association of the gap junction protein connexin-43 with $\mathrm{ZO}-1$ in cardiac myocytes. J Biol Chem, 273, 12725-12731.

Traub, O., Look, J., Dermietzel, R., Brummer, F., Hulser, D., and Willecke, K. (1989). Comparative characterization of the $21-\mathrm{kD}$ and $26-\mathrm{kD}$ gap junction proteins in murine liver and cultured hepatocytes. J Cell Biol, 108, 1039-1051.

Traub, O., Look, J., Paul, D., and Willecke, K. (1987). Cyclic adenosine monophosphate stimulates biosynthesis and phosphorylation of the $26 \mathrm{kDa}$ gap junction protein in cultured mouse hepatocytes. Eur J Cell Biol, 43, 48-54.

Turmel, P., Dufresne, J., Hermo, L., et al. (2011). Characterization of pannexin1 and pannexin 3 and their regulation by androgens in the male reproductive tract of the adult rat. Mol Reprod Dev, 78, 124-138.

Ultanir, S. K., Hertz, N. T., Li, G., et al. (2012). Chemical genetic identification of NDR1/2 kinase substrates AAK1 and Rabin8 Uncovers their roles in dendrite arborization and spine development. Neuron, 73, 1127-1142.

Urschel, S., Hoher, T., Schubert, T., et al. (2006). Protein kinase A-mediated phosphorylation of connexin36 in mouse retina results in decreased gap junctional communication between AII amacrine cells. J Biol Chem, 281, 3316333171.

van Rijen, H. V., van Veen, T. A., Hermans, M. M., and Jongsma, H. J. (2000). Human connexin 40 gap junction channels are modulated by cAMP. Cardiovasc Res, 45 , 941-951.

van Veen, T. A., van Rijen, H. V., and Jongsma, H. J. (2000). Electrical conductance of mouse connexin45 gap junction channels is modulated by phosphorylation. Cardiovasc Res, 46, 496-510.

Vanhaecke, T., Papeleu, P., Elaut, G., and Rogiers, V. (2004). Trichostatin A-like hydroxamate histone deacetylase inhibitors as therapeutic agents: toxicological point of view. Curr Med Chem, 11, 1629-1643.

Verselis, V. K., Ginter, C. S., and Bargiello, T. A. (1994). Opposite voltage gating polarities of two closely related connexins. Nature, 368, 348-351.

Vinken, M., Decrock, E., Leybaert, L., et al. (2011). Non-channel functions of connexins in cell growth and cell death. Biochim Biophys Acta, 1818, 2002-2008.

Vinken, M., Henkens, T., Vanhaecke, T., et al. (2006). Trichostatin a enhances gap junctional intercellular communication in primary cultures of adult rat hepatocytes. Toxicol Sci, 91, 484-492. 
Wagner, S. A., Beli, P., Weinert, B. T., et al. (2011). A proteome-wide, quantitative survey of in vivo ubiquitylation sites reveals widespread regulatory roles. Mol Cell Proteomics, 10, M111 013284.

Wang, N., De Bock, M., Decrock, E., et al. (2012). Paracrine signaling through plasma membrane hemichannels. Biochim Biophys Acta.

Wang, Y., and Mehta, P. P. (1995). Facilitation of gap-junctional communication and gap-junction formation in mammalian cells by inhibition of glycosylation. Eur J Cell Biol, 67, 285-296.

Wang, Y., Mehta, P. P., and Rose, B. (1995). Inhibition of glycosylation induces formation of open connexin-43 cell-to-cell channels and phosphorylation and triton X-100 insolubility of connexin-43. J Biol Chem, 270, 26581-26585.

Warn-Cramer, B. J., Cottrell, G. T., Burt, J. M., and Lau, A. F. (1998). Regulation of connexin-43 gap junctional intercellular communication by mitogen-activated protein kinase. J Biol Chem, 273, 9188-9196.

Warn-Cramer, B. J., Lampe, P. D., Kurata, W. E., et al. (1996). Characterization of the mitogen-activated protein kinase phosphorylation sites on the connexin-43 gap junction protein. J Biol Chem, 271, 3779-3786.

Wayakanon, P., Bhattacharjee, R., Nakahama, K., and Morita, I. (2012). The role of the Cx43 C-terminus in GJ plaque formation and internalization. Biochem Biophys Res Commun, 420, 456-461.

White, T. W., Bruzzone, R., Goodenough, D. A., and Paul, D. L. (1992). Mouse Cx50, a functional member of the connexin family of gap junction proteins, is the lens fiber protein MP70. Mol Biol Cell, 3, 711-720.

White, T. W., Bruzzone, R., and Paul, D. L. (1995). The connexin family of intercellular channel forming proteins. Kidney Int, 48, 1148-1157.

Wisniewski, J. R., Nagaraj, N., Zougman, A., Gnad, F., and Mann, M. (2010). Brain phosphoproteome obtained by a FASP-based method reveals plasma membrane protein topology. J Proteome Res, 9, 3280-3289.

Xia, C. H., Cheng, C., Huang, Q., et al. (2006). Absence of alpha3 (Cx46) and alpha8 ( $\mathrm{Cx} 50$ ) connexins leads to cataracts by affecting lens inner fiber cells. Exp Eye Res, 83, 688-696.

Xiao, F., Weng, J., Fan, K., and Wang, W. (2011). Detailed regulatory mechanism of the interaction between Z0-1 PDZ2 and connexin43 revealed by MD simulations. PLoS One, 6, e21527.

Xie, H., Laird, D. W., Chang, T. H., and Hu, V. W. (1997). A mitosis-specific phosphorylation of the gap junction protein connexin43 in human vascular cells: biochemical characterization and localization. J Cell Biol, 137, 203-210.

Yang, X. J., and Seto, E. (2008). Lysine acetylation: codified crosstalk with other posttranslational modifications. Mol Cell, 31, 449-461.

Yates, J. R., 3rd, Gilchrist, A., Howell, K. E., and Bergeron, J. J. (2005). Proteomics of organelles and large cellular structures. Nat Rev Mol Cell Biol, 6, 702-714.

Yen, M. R., and Saier, M. H., Jr. (2007). Gap junctional proteins of animals: the innexin/pannexin superfamily. Prog Biophys Mol Biol, 94, 5-14.

Yin, X., Gu, S., and Jiang, J. X. (2001). Regulation of lens connexin 45.6 by apoptotic protease, caspase-3. Cell Commun Adhes, 8, 373-376.

Yin, X., Jedrzejewski, P. T., and Jiang, J. X. (2000). Casein kinase II phosphorylates lens connexin 45.6 and is involved in its degradation. J Biol Chem, 275, 6850-6856. 
Yin, X., Liu, J., and Jiang, J. X. (2008). Lens fiber connexin turnover and caspase-3mediated cleavage are regulated alternately by phosphorylation. Cell Commun Adhes, 15, 1-11.

Yogo, K., Ogawa, T., Akiyama, M., Ishida, N., and Takeya, T. (2002). Identification and functional analysis of novel phosphorylation sites in $\mathrm{Cx} 43$ in rat primary granulosa cells. FEBS Lett, 531, 132-136.

Zampighi, G. A., Planells, A. M., Lin, D., and Takemoto, D. (2005). Regulation of lens cell-to-cell communication by activation of PKCgamma and disassembly of Cx50 channels. Invest Ophthalmol Vis Sci, 46, 3247-3255.

Zappala, A., Cicero, D., Serapide, M. F., et al. (2006). Expression of pannexin1 in the CNS of adult mouse: cellular localization and effect of 4-aminopyridine-induced seizures. Neuroscience, 141, 167-178.

Zhang, L., Deng, T., Sun, Y., Liu, K., Yang, Y., and Zheng, X. (2008). Role for nitric oxide in permeability of hippocampal neuronal hemichannels during oxygen glucose deprivation. J Neurosci Res, 86, 2281-2291.

Zhang, Y. W., Nakayama, K., Nakayama, K., and Morita, I. (2003). A novel route for connexin 43 to inhibit cell proliferation: negative regulation of S-phase kinaseassociated protein (Skp 2). Cancer Res, 63, 1623-1630.

Zhou, L., Kasperek, E. M., and Nicholson, B. J. (1999). Dissection of the molecular basis of pp60(v-src) induced gating of connexin 43 gap junction channels. J Cell Biol, $144,1033-1045$. 